Florida International University FIU Digital Commons

7-24-2003

\title{
The benefits of a regular exercise group program in community dwelling elders with chronic stroke
}

Dessislava Dakova

Florida International University

DOI: $10.25148 /$ etd.FI14061589

Follow this and additional works at: https://digitalcommons.fiu.edu/etd

Part of the Physical Therapy Commons

\section{Recommended Citation}

Dakova, Dessislava, "The benefits of a regular exercise group program in community dwelling elders with chronic stroke" (2003). FIU Electronic Theses and Dissertations. 2707.

https://digitalcommons.fiu.edu/etd/2707 


\title{
FLORIDA INTERNATIONAL UNIVERSITY \\ Miami, Florida
}

\section{THE BENEFITS OF A REGULAR EXERCISE GROUP PROGRAM IN COMMUNITY DWELLING ELDERS WITH CHRONIC STROKE}

\author{
A thesis submitted in partial fulfillment of the \\ requirements for the degree of \\ MASTER OF SCIENCE \\ in \\ PHYSICAL THERAPY \\ by \\ Dessislava Dakova
}


To: Dean Ronald M. Berkman

College of Health and Urban Affairs

This thesis, written by Dessislava Dakova, and entitled The Benefits of a Regular Exercise Group Program in Community Dwelling Elders with Chronic Stroke, having been approved in respect to style and intellectual content, is referred to you for judgment.

We have read this thesis and recommend that it be approved.

Neva Kirk-Sanchez

Esther Ball-Llovera

Helen Cornely, Major Professor

Date of Defense: July 24, 2003

The thesis of Dessislava Dakova is approved.

Dean Ronald M. Berkman College of Health and Urban Affairs

Dean Douglas Wartzok University Graduate School

Florida International University, 2003 


\section{DEDICATION}

To my parents, Vera and Dimitar, thank you for your love, encouragement, dedication, and faith in me. I love you. 


\section{ACKNOWLEDGMENTS}

I would like to thank the members of my committee, Helen Cornely, Neva KirkSanchez, and Esther Ball-Llovera for all of their assistance and help. I would like to express my appreciation to South Miami Hospital research committee, and especially to Kelly Cohn and Pat Collins, for all their hard work, research, and advice.

Very special thanks must go to my mother, Dr. Vera Koicheva for all the encouragement, advice and long hours of research without which this project would have never been completed. 


\title{
ABSTRACT OF THE THESIS \\ THE BENEFITS OF A REGULAR EXERCISE GROUP PROGRAM IN COMMUNITY DWELLING ELDERS WITH CHRONIC STROKE
} by

\author{
Dessislava Dakova
}

Florida International University, 2003

\author{
Miami, Florida \\ Professor Helen Cornely, Major professor
}

The purpose of this study was to investigate whether community dwelling elders with chronic stroke who participate in a regular exercise group program demonstrate decreased fear of falls, decreased depression and improved quality of life/health status perception as compared to community dwelling elders with chronic stroke who don't participate in such an exercise program.

Two groups of 13 English speaking community dwelling elders with chronic stroke, were selected. The first group consisted of individuals who were currently participating in the Adult Fitness Group at South Miami Hospital (SMH) and the second group consisted of former SMH patients who had not been participating in any exercise programs since discharge from the hospital.

Fall related self-efficacy was measured using the Falls-Efficacy scale (FES). Severity of depression was assessed with the Geriatric Depression Scale short form. Quality of life/perceived health status was assessed with the Health Assessment Questionnaire@. 
A significant difference was found only in the depression variable $(\mathrm{P}=.02)$. Significant differences were found for all the variables, falls efficacy $(\mathrm{P}=.01)$, depression $(\mathrm{P}=.000)$ and health assessment $(\mathrm{P}=.00)$ between the pre and post involvement in the Adult Fitness group for the experimental group. Significant negative correlations were found between the falls efficacy and health assessment $(r=-.804 p<.01)$ and falls efficacy and depression $(r=-.488 p<.05)$, and a positive correlation was found between depression and health assessment $(r=.524 \mathrm{p}<.01)$ in the experimental and control group as a whole.

Participation in a regular exercise program could be an effective way to decrease depression in community dwelling elders with chronic stroke. The relationship between fear of falls and quality of life in this research is inconclusive. Further research is needed to establish whether regular exercise can help to decrease fear of falls and increase quality of life in elders with chronic stroke. 


\section{TABLE OF CONTENTS}

CHAPTER

PAGE

I. INTRODUCTION

Statement of the Problem

Objective 3

Research Questions

Relevance/Significance

Research Hypothesis

Definitions

Assumptions

4

4

5

5

6

II. REVIEW OF LITERATURE

Stroke

Exercise and Functional Recovery

Falls

Depression

Quality of Life

Summary of Review of Literature

III. METHODOLOGY

Research Hypothesis

Subjects

Inclusion Criteria

Adult Fitness Group

Procedures

25

Instruments

IV. RESULTS

Demographics

Fall-Efficacy Scale

Geriatric Depression Scale

Health Assessment Questionnaire

Correlations

T- Tests

V. DISCUSSION AND CONCLUSION

REFERENCES 


\section{LIST OF TABLES}

TABLE

PAGE

Table 1 Demographic characteristics for the experimental and control groups.

Table 2 Mean, minimum-maximum and difference in the instrument scores for the experimental (post-exercise enrolment) and control groups.

Table 3 Mean (SD) and median for FES for the experimental (post-exercise enrolment) and control groups

Table 4 Mean (SD) and median for GDS for the experimental (post-exercise enrolment) and control groups.

Table 5 Correlations between the instruments for both groups as a whole.

Table 6 Correlations between the instruments for the experimental group for post-exercise enrolment.

Table 7 Correlations between the instruments for the control group.

Table 8 Correlations between the instruments for the experimental group for pre-exercise enrolment.

Table 9 Mean, minimum-maximum and difference in instrument scores for the experimental group for pre- and post- exercise group enrollment. 


\section{CHAPTER I}

\section{INTRODUCTION}

Stroke is the most disabling chronic disease in the Western world and continues to be a major health problem. Stroke has been reported to be the third leading cause of death in the United States, after heart disease and cancer, and it leaves many survivors with permanent physical and mental disabilities. ${ }^{1}$ During the past 10 years, the incidence of stroke has increased, while at the same time, stroke mortality has declined, ${ }^{1}$ which suggests that the number of patients with chronic stroke has also increased. Brandstater ${ }^{2}$ reported that there are 1.5 million survivors of stroke in the United States and that approximately half of these individuals have significant persisting neurological impairments and physical disability. A stroke can occur at any age, but $72 \%$ of people affected by stroke are 65 years old or ólder. ${ }^{3}$

Stroke, or cerebrovascular accident, occurs secondary to restricted blood supply (ischemia) or by hemorrhage into the brain tissue, resulting in cell damage and impaired neurological function, which leads to a sudden focal neurological deficit. ${ }^{4}$ Stroke mortality rates differ substantially by sex and race, with men having a mortality ratio $25 \%$ higher than women, and blacks having a ratio $40 \%$ higher than whites. ${ }^{5}$ Risk factors include hypertension, diabetes, coronary artery disease, smoking, obesity, stress, and sedentary life style. ${ }^{6}$ Stroke related morbidity varies greatly and may range from mild physical weakness to profound mental and physical impairments, coma and death.

Stroke is not only an important health problem, but it also imposes sociologic and economic burdens on the patients and caregivers. During the last few decades, rehabilitation has become a necessary element in stroke care. ${ }^{7}$ Evans and colleagues ${ }^{8}$ 
observed patients who participated in rehabilitation and those who did not participate. Their results suggest that rehabilitation participants had lower mortality at follow-up, fewer discharges to a nursing home, fewer re-hospitalization days and frequency than patients who did not participate in rehabilitation therapy. Physical rehabilitation of patients with stroke aims to maximize the recovery of functional loss, walking ability, and self-sufficiency as well as to help the patient regain a psychosocial role. ${ }^{9}$ Further, rehabilitation helps to address the significant emotional impact of decreased functional ability and increased dependency, which very often results in depression, fear of falling during gait and activities of daily living (ADLs) and decreased perception of quality of life. Subsequently, the demand for stroke rehabilitation services continues to increase and there is a growing need to optimize both the effectiveness and the efficiency of the rehabilitation care. ${ }^{10}$

Statement of the Problem

There are three aspects of the research problem:

1. The higher incidence of fear of falls in patients with chronic stroke: It has been found that during a 4-month period survivors of stroke had twice the risk of falling as compared to population controls ${ }^{11}$ and that survivors of stroke continued to experience falls far beyond the 6 and 12-month post stroke period. ${ }^{12}$ The loss of confidence, or "fear of falling" which occurs in the majority of survivors of stroke may prevent them from performing activities of daily living (ADLs), therefore, fear of falling could be a cause of future physical dependence and fewer social contacts. ${ }^{13}$ Loss of confidence and fear of falling were found to be an independent risk factor for functional decline, lower life satisfaction, depressed mood, frailty, and balance deterioration. ${ }^{13}$ 
2. The higher incidence of depression in patients with chronic stroke: Depression is one of the most common emotional disorders associated with major health issues including stroke. Post-stroke depression (PSD) has been considered as the most frequent and important neuropsychiatric consequence of stroke, since at least one third of the survivors of stroke experience depression both early and late post stroke ${ }^{14}$ and since this condition can have an adverse impact on cognitive function, ${ }^{15}$ functional recovery, ${ }^{16}$ and survival. ${ }^{17}$ The incidence of PSD 1 year post stroke was found to range from 18 to $61 \% .^{18,19}$

3. The higher incidence of low quality of life/health status perception in patients with chronic stroke: When compared to the community-dwelling seniors who have not experienced a stroke, survivors of stroke report a lower sense of well-being, are more likely to be restricted in their cognitive and physical function, and have a greater number of comorbid conditions. ${ }^{20} \mathrm{~A}$ study by Clarke et $\mathrm{al}^{20}$ showed that functional disabilities in instrumental activities of daily living (IADL) are associated with reduced sense of wellbeing, particularly in terms of survivors' sense of mastery and control of their lives, their perceived opportunities for personal growth, and their ability to engage in positive social relationships. Depression and disability were found to be the strongest predictors of overall, psychosocial, and physical quality of life (QOL) ${ }^{21}$

Objective

The purpose of this study was to investigate whether community dwelling elders with chronic stroke who participate in a regular group exercise program demonstrate decreased fear of falls, decreased depression and improved health status perception as 
compared to community dwelling elders with chronic stroke who don't participate in such an exercise program.

Research Questions

Question \#1: Do community dwelling elders with chronic stroke participating in a regular group exercise program demonstrate decreased fear of falls as compared to community dwelling elders with chronic stroke who don't participate in such a program?

Question \#2: Are community dwelling elders with chronic stroke participating in a regular group exercise program less depressed than community dwelling elders with chronic stroke who don't participate in such a program?

Question \#3: Do community dwelling elders with chronic stroke participating in a regular group exercise program demonstrate higher health status perception as compared to community dwelling elders with chronic stroke who don't participate in such a program?

\section{Relevance/Significance}

The results of this research will help to determine the effectiveness of a regular exercise group program for community dwelling elders with chronic stroke to reduce the fear of falls and depression and increase the health status perception. This would assist to establish such a program as an effective way to continue with post stroke rehabilitation once the patient has been discharged from the hospital and outpatient physical therapy. Further, the results of the study would help to provide a stronger argument that continuing physical exercise can also be effective in improving the health status and general well-being of community dwelling elders with chronic stroke, which would 
further help to establish community exercise programs as an important and necessary part of the rehabilitation of patients with chronic stroke.

Research Hypothesis

Community dwelling elders with chronic stroke who participate in a regular exercise group program demonstrate decreased fear of falls, decreased depression and improved quality of life/health status perception as compared to community dwelling elders with chronic stroke who don't participate in such an exercise program.

\section{Definitions}

Stroke or cerebrovascular accident: A pathologic condition secondary to restricted blood supply (ischemia) or by hemorrhage into the brain tissue, resulting in cell damage and impaired neurological function, which leads to a sudden focal neurological deficit. ${ }^{4}$

Fear of falling: Loss of self-confidence and self-imposed functional limitations in both home-living and institutionalized elderly persons who have fallen ${ }^{22}$; lasting concern about falling that leads to the individual avoiding activities that he/she remains capable of performing. $^{23}$

Fall: An unintentional event where the person comes to be on the floor without the feet weight-bearing. ${ }^{24}$

Falls efficacy: The degree of confidence a person has in performing common daily activities without falling. ${ }^{25}$

Quality of life (QOL): Individuals' perception of their position in life in the context of the culture and value system in which they live and in relation to their goals, expectations, standards, and concerns. ${ }^{26}$ 
Patients with chronic stroke: Patients with history of stroke of more than 1 year.

\section{Assumptions}

1. All subjects fully understood the contents of the questionnaires with the help of the researcher when necessary.

2. All information given by the subjects was truthful and accurate to the best of their abilities.

3. The Falls-Efficacy scale (FES), the Geriatric Depression Scale short form and the Health Assessment Questionnaire are valid and reliable instruments.

4. All instruments were administered and scored in a consistent manner for all subjects. 


\section{CHAPTER II}

\section{REVIEW OF LITERATURE}

Stroke has been reported to be the third leading cause of death in the United States, after heart disease and cancer, and it leaves many survivors with permanent physical and mental disabilities. ${ }^{1}$ During the past 10 years, the number of stroke hospitalizations has increased from 592,811 to 821,760 , while at the same time, stroke mortality has declined to 25.9 per $100000 .{ }^{1}$ This suggests that the number of patients with chronic stroke has also increased. Brandstater ${ }^{2}$ reported that there are 1.5 million survivors of stroke in the United States and that approximately half of these individuals have significant persisting neurological impairments and physical disability. The prevalence of survivors of stroke with incomplete recovery has been estimated at $460 / 100,000^{27}$ and the percentage of Americans with partial or complete disability between $24 \%$ and $54 \%{ }^{28}$

Stroke

Stroke, or cerebrovascular accident, occurs secondary to restricted blood supply (ischemia) or by hemorrhage into the brain tissue, resulting in cell damage and impaired neurological function, which leads to a sudden focal neurological deficit. ${ }^{4}$ Stroke mortality rates differ substantially by sex and race, with men having a mortality ratio $25 \%$ higher than women, and blacks having a ratio $40 \%$ higher than withes. ${ }^{5}$ Risk factors include hypertension, diabetes, coronary artery disease, smoking, obesity, stress, previous history of stroke, and sedentary life style. ${ }^{6}$ Even though stroke can occur at any age ${ }^{3}$, its incidence raises rapidly with age and in the 80-90 year old age group the mortality rate approaches the incidence rate. $^{29}$ 
The neurological manifestations of stroke reflect the location and size of the affected area and may be bilateral or unilateral. Deficits may result in hemiplegia (motor control dysfunction), decreased balance, spasticity (increased tone), paresis, sensory impairments, speech impairments, cognitive impairments, memory deficits, personality and behavior changes. Further, depending on which hemisphere is affected, certain perceptual deficits may result. Left hemisphere lesions may result in general language deficits, difficulty initiating tasks, compulsive behavior, extreme distractibility, and low frustration levels. ${ }^{29}$ Right hemisphere lesions usually result in visual-perceptual deficits such as spatial relationships and position in space, poor judgment and unrealistic behavior, denial of disability, difficulty retaining information, irritability and confusion. ${ }^{29}$ The degree of neurological involvement varies greatly and may range from complete recovery to profound physical and cognitive impairments, coma and death. Exercise and Functional Recovery

Although it has been found that most recovery of function occurs in the first three months following stroke $\mathrm{e}^{30,31,32}$ there is a growing body of evidence demonstrating that with training, individuals at least six months post stroke can improve the performance of functional tasks ${ }^{33,34,35,36,37,38}$ and aerobic capacity. ${ }^{39}$ Research demonstrates that with intervention, subjects with chronic stroke are able to improve the performance of

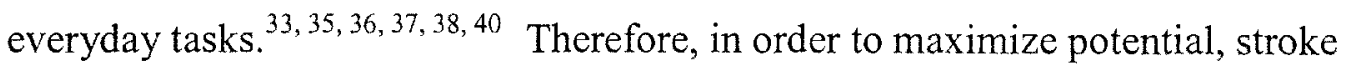
rehabilitation needs to continue on the long term, rather than cease in 3 months to 1 year post stroke. ${ }^{30,35}$ Despite this evidence, Dean et al ${ }^{35}$ suggested that training programs appear to be available only to participants in research projects and only during the duration of the project. 
Currently, most survivors of stroke are thought to have achieved their maximum recovery by means of standard rehabilitative therapies within 3 to 6 months post stroke onset $^{2}$. During this relatively brief period, patients are normally offered intensive rehabilitative care, after which they are typically discharged to routine medical follow-up with few recommendations for additional therapeutic interventions to promote cardiovascular fitness and optimize neuromuscular function. Consequently, most patients are relegated to an inherently sedentary lifestyle and its associated health risks including substantial deconditioning, increased cardiovascular risk, and social isolation. One of the most consistent observations in patients with stroke is that they spend a large proportion of the day alone and inactive ${ }^{41}$ Belmont and colleagues ${ }^{42}$ observed that survivors of stroke are less likely to complete practice when left unattended. These observations suggest that individuals with chronic stroke are at risk of becoming socially isolated and more disabled after discharge from rehabilitation, particularly since most of them are discharged with functional ambulation skills that are inferior to the level required for effective community ambulation. ${ }^{43,44}$ Hence, there is an urgent need to develop an easily accessible program, which would provide the patient with the opportunity to continue with exercise activities post formal physical rehabilitation discharge.

Accessible ongoing programs that are designed to increase the strength of the affected side and improve functional performance may not only decrease depression and improve the quality of life perception, but may also reduce the need for and duration of future institutionalized care. ${ }^{35}$ Group exercise classes are one way to provide ongoing programs to maintain and/or improve performance after discharge from rehabilitation. Such classes are advantageous because they not only provide the opportunity for exercise 
and social interaction, but are also cost-effective with several individuals participating at the same time. ${ }^{35}$

Dean et al ${ }^{35}$ investigated the feasibility and efficacy of an exercise class on improving the performance and endurance of functional tasks involving the lower extremities (sit-to-stand, walking, reaching in sitting and standing, walking, and stair ascent and descent). The major finding of this pilot study was that subjects with chronic stroke who participated regularly in a 4-week, physiotherapist supervised group exercise class, demonstrated improvement that was specific to training. Over the training period, walking speed and endurance, force production through the affected foot during sit-to stand, and the ability to balance on the affected leg while stepping (step test) improved. Moreover, these improvements were maintained for 2 months after the cessation of training.

Research also demonstrates that exercise and task-oriented exercise programs improve strength and timing of muscle activation, cardiovascular fitness, and functional motor performance. ${ }^{40,45}$ Several studies provided evidence that 3 months of treadmill training improved leg strength and floor walking performance. At the same time, it reduced paretic leg hamstring spasticity and the energy cost of the hemiparetic gait, suggesting improved gross motor efficiency ${ }^{46,47,48}$ According to these studies, treadmill training increased peak exercise capacity while reducing the energy cost of the hemiparetic ambulation, thereby improving the physiologic fitness reserve in older patients with stroke who had chronic mild-to-moderate gait impairments. It is quite possible that the substantial gains in volitional strength observed in these studies merely reflected the overcoming of the physical deconditioning associated with the sedentary life 
style of the patient with chronic stroke. Thus, these results suggest that the detrimental effect of longstanding physical deconditioning can be reversed or considerably reduced by a regular "task-oriented" aerobic exercise program.

Teixeira-Salmela et al ${ }^{49}$ evaluated the impact of a program of muscle strengthening and physical conditioning on impairments and disability in subjects with chronic stroke. The results of this study showed significant improvements in all measures (quality of life assessment, lower extremity muscle strength assessment, lower extremity muscle tone assessment, walking speed assessment, stair climbing) in subjects after a 10 week training program. Brinkmann and Hoskins ${ }^{50}$ also reported that 12 weeks of bicycle training was an effective way of improving both the functional status and self-concept of subjects with chronic stroke. Psychological gains may have resulted from perceived positive sensation in both limbs and muscles and increased perceptions of strength and control during training. These gains may have also been attributed to positive feedback from successes attained during training, from subjective appreciation of the program, enjoyment and socialization associated with subject-investigator interaction. ${ }^{11}$ The rehabilitation value of the psychological gains in subjective perceptions should not be underestimated with disabled groups who are at the risk of functional decline. The self satisfaction and greater confidence in engaging in physical activities informally reported by all subjects may have enabled them not only to realize their own potential but also to better accept their disability and to deal with it more effectively. ${ }^{50}$ Falls

Most of the studies on falls and fear of falling are done on older individuals where advanced age, decreased vestibular apparatus function, poor vision and proprioception, 
and polypharmacy have been found to be the major predictors of falls. In patients with chronic stroke, in addition to the above-mentioned factors, spasticity, depression, deconditionig, and impairments in the cognition and motor function further increase the risk of falling. Hyndman et al ${ }^{12}$ showed that survivors of stroke continued to experience falls far beyond the 6 and 12-month post stroke period. Jorgensen et al ${ }^{11}$ showed that during a 4-month period survivors of stroke had twice the risk of falling as compared to population controls and also found a relationship between depressive symptoms and falls. The high proportion of marked depressive symptoms in their patients with stroke was similar to that found in other community studies of patients with chronic stroke. ${ }^{51,52}$ Depression may lead to reduced attention thereby to an increased risk of falling. A possible alternative explanation however, is that falls may lead to a decline in mobility, which further increases disability and may result in depression. Therefore, research indicates that there is a significant relationship between depression and functional abilities, but it is inconclusive about which one is the cause and which one is the effect. Nyberg and Gustavson ${ }^{7}$ suggested that $14 \%$ to $39 \%$ of people with stroke had 1 or more falls during their hospital stay where others studies reported that approximately $75 \%$ of the individuals with stroke have fallen in the 6 months after discharge from hospital. ${ }^{11,53}$ Research has identified specific risk factors for falls in people with stroke; fallers have shown greater standing sway, impulsivity, and slowed response times in addition to greater postural sway and reduced force generation when standing up and sitting down, ${ }^{54}$ impaired postural stability, and bilateral motor impairment. ${ }^{7}$ The important interaction between mobility disorders and falls is highlighted by epidemiologic case-control studies conducted to identify risk factors that increase the 
likelihood of falling. Taken together, these studies indicate that lower extremity weakness, gait and balance disorders, previous falls, functional impairment, visual deficits, cognitive impairment, depression, and multiple drugs are the most important risk factors for falls in patients with chronic stroke. ${ }^{7,11,53,54}$

Falling may result in physical and psychological trauma, leading to a self-imposed restriction of activity. ${ }^{55}$ This loss of confidence, or "fear of falling", occurs in the majority of survivors of stroke, and it has also been observed in patients who have not experienced any previous fall. Reduced confidence may prevent survivors of stroke from performing activities of daily living (ADLs), therefore, fear of falling could be a cause of future physical dependence and fewer social contacts. ${ }^{13}$ Loss of confidence and fear of falling were found to be an independent risk factor for functional decline, lower life satisfaction, depressed mood, frailty, and balance deterioration. ${ }^{13}$ Restricted physical activity from fear of falling may result in muscle atrophy, loss of muscular and aerobic endurance, loss of coordination, and loss of flexibility; thus, the self imposed restriction of activity may limit the risk of falling but may also contribute to further functional decline.

Numerous clinical approaches have been advocated for addressing the complex and serious concerns of falls and mobility problems in older persons. Many of these approaches have demonstrated efficacy and have become a part of evidence-based guidelines to develop effective programs to increase mobility and decrease the incidents of falls in the elderly. Cheng et al ${ }^{54}$ described the role of symmetrical body weight distribution training in preventing falls among patients with hemiplegic stroke and concluded that training may improve sit-to stand performance and consequently, decrease 
the number of falls by patients with stroke. Puisieux et al ${ }^{56}$ showed that falls prevention through a home based, multidisciplinary, low-cost intervention, in which physical therapy, drug treatment modification, and environmental changes are key components, can reduce the risk of falls in a elderly population of fallers. Jorgensen et $\mathrm{al}^{11}$ suggested that falls prevention in survivors of stroke should focus on intrinsic factors, particularly mobility and depression, the most prevalent risk factors in survivors of chronic stroke. ${ }^{55}$ Exercise, Tai Chi, and other interventions may also be effective in minimizing the risk of falls, ${ }^{57,58}$ and have multiple benefits such as improved balance, reduced fear of falling and increased likelihood of falling in a way so as to avoid injury. Among elderly people in general, individually prescribed exercise programs have been shown to reduce the number of falls. ${ }^{39,59,60}$

In general most studies examine elderly people and inpatients in a hospital setting. Minimal literature is available on survivors with chronic stroke who have been formally discharged from physical rehabilitation and limited information is available on whether a participation in regular specialized exercise program reduces fear of falling and falls in the participants. Clearly, research about falls is incomplete. Several researchers have already discussed the need for information to identify the role of exercise and optimum levels of activity in order to reduce falls and enhance functional ability. ${ }^{61}$ Efforts to develop and evaluate fall-intervention assessment and intervention protocols for the stroke survivors are necessary.

Depression

Depression is one of the most common emotional disorders associated with major health issues including stroke. Numerous studies have found that in the acute hospital the 
mean prevalence of major depression was $20 \%$ and of minor depression was $21 \%{ }^{15}$ Similar findings have been reported in rehabilitation hospitals and outpatient clinics. ${ }^{17}$ In most cases, depression has been associated with functional abilities, personality, and previous history of depression.

Post-stroke depression (PSD) is the most frequent and important neuropsychiatric consequence of stroke, since at least one third of the survivors of stroke experience depression both early and late post stroke ${ }^{14}$ and since this condition can have an adverse impact on cognitive function, ${ }^{15}$ functional recovery, ${ }^{16}$ and survival. ${ }^{17}$ The incidence of PSD 1 year post stroke was found to be $38.7 \%$ by Aben et al. ${ }^{18}$ The results of studies on the frequency, causes, and consequences of PSD have been, however, remarkably variable and controversial. For example, the estimates of the incidence of PSD range widely from 18 to $61 \% .{ }^{19}$ Further, the cause of PSD is still highly debated. The proponents of the neuroanatomical model published first in 1980's by Robinson's team, propose that the presence of major depression is usually caused by a lesion in the left frontal areas of the brain. ${ }^{15}$ The supporters of the psychological theory, on the other hand, explain PSD with psychological adjustments after major disease. ${ }^{14}$

Several studies have found that depression has a negative effect on the recovery of physical impairment and ADLs after stroke. ${ }^{18,62}$ Aben et al $^{18}$ found that 2 years after the stroke, patients with in-hospital depression had significantly less recovery of ADL functions than non-depressed patients and that remission of depression was associated with greater recovery in $\mathrm{ADL}$ functions. Watkins et al ${ }^{63}$ also suggested that the rehabilitation of depressed patients with stroke is more difficult than the rehabilitation of patients who are not depressed: their recovery in the hospital is slower and less 
successful, they are less likely to regain normal life style after discharge, and they have poorer survival rates in a long term. Their data have been confirmed by the study of House et al, ${ }^{19}$ which showed that the presence of PSD 1 month after stroke increase the risk of mortality 12 and 24 months later.

In general, most of the studies on PSD focus on the pharmacological treatment of depression, lesion location, and its effect on ADL performance. It is still unclear whether decreased functional abilities are the cause or the consequence of PSD. It is quite possible that depression may develop secondary to significant functional limitations, dependence from family and friends, social isolation and change of work status. On the other hand, depression may greatly affect one's participation in the rehabilitation process and result in decreased motivation, decreased effort, and less functional progress. Further, the research on the effect of physical exercise and group exercise programs on PSD has been scarce and there is a need to determine whether such programs could be used as an alternative way to increase social interaction and decrease depression in patients with chronic stroke. Quality Of Life (QOL)

Most of the research on stroke has concentrated on stroke incidence, mortality, stroke related disability and functional recovery, and only lately, attention has been given to the survivors' life satisfaction after stroke. Regardless of the extent of measurable functional limitations, stroke may be responsible for a wide range of emotional impairments and a significant change in quality of life and well-being perception. As defined by the World Health Organization Quality of Life (WHOQOL) Group, QOL refers to the individuals' perceptions of their position in life in the context of the culture 
and value system in which they live and in relation to their goals, expectations, standards and concerns. ${ }^{64}$ Therefore, it is imperative that such an important issue as QOL should also be included in the assessment and treatment of the survivor of stroke.

When compared to community-dwelling seniors who have not experienced a stroke, survivors of stroke report a lower sense of well-being, are more likely to be restricted in their cognitive and physical function, and have a greater number of comorbid conditions. ${ }^{20}$ In many cases, a significant decrease in QOL persists in patients independent in ADL, but still not performing at pre stroke functional level. Failure to recover the ability to work is also a major source of low QOL especially for people aged less than 65 years. ${ }^{21}$ A study by Clarke et $\mathrm{al}^{20}$ showed that functional disabilities in IADL are associated with reduced sense of well-being, particularly in terms of survivors' sense of mastery and control of their lives, their perceived opportunities for personal growth, and their ability to engage in positive social relationships.

A study by Carod-Artal et $\mathrm{al}^{21}$ provides information regarding the variables that had the greatest impact on the QOL of patients treated in a stroke unit 1 year post stroke. Depression and disability were the strongest predictors of overall, psychosocial, and physical QOL. Variables reported to be consistently associated with lower QOL or life satisfaction in survivors of stroke were depression, lower functional status and greater severity of paralysis. ${ }^{65}$ Post stroke disability was a stronger predictor of low QOL than post stroke depression 1 year post stroke. Patients with severe/moderate disability had lower QOL than depressed patients with less disability. Isolation and diminished social activities were the result of physical disability more than post stroke depression. Older 
age or lower educational level, according to this study, was not correlated with low QOL. Carod-Artal et al also identified functional status and depression as predictors of QOL. ${ }^{21}$

Although both physical and cognitive disabilities constrain the subjective wellbeing of the community dwelling survivors of chronic stroke, social resources can moderate the adverse effects of residual disabilities. Survivors with adequate social support are less adversely affected by functional dependence, perceive greater opportunities for personal growth and report more positive relationships with others. ${ }^{20}$ Social support has elsewhere been found to be associated with higher quality of life in stroke survivors. ${ }^{65,66,67,68}$ Therefore, enhancing the support system and providing easier access to community programs and support groups could greatly benefit the patient with chronic stroke. A group exercise program could enable the individual to continue with the physical rehabilitation while at the same time would provide the opportunity to go out in the community, form relationships and share experiences with other survivors of stroke. Summary of Review of Literature

Stroke, or cerebrovascular accident, occurs secondary to restricted blood supply (ischemia) or by hemorrhage into the brain tissue, resulting in cell damage and impaired neurological function, which leads to a sudden focal neurological deficit. ${ }^{4}$ Stroke has been reported to be the third leading cause of death in the United States, after heart disease and cancer, and it leaves many survivors with permanent physical and mental disabilities. ${ }^{1}$

During the past 10 years, the number of stroke hospitalizations has increased while at the same time, stroke mortality has declined, 'which suggests that the number of patients with chronic stroke has also increased. It has been estimated that there are 1.5 million survivors of stroke in the United States ${ }^{2}$ and that approximately half of these individuals 
have significant persisting neurological impairments and physical disability. Statistics of stroke show that men are more affected than women and blacks have $40 \%$ higher stroke incidence as compared to whites. ${ }^{5}$ Risk factors include hypertension, diabetes, coronary artery disease, smoking, obesity, stress, previous history of stroke, and sedentary life style. ${ }^{6}$ The neurological manifestations of stroke reflect the location and size of the affected area and neurological involvement varies between complete recovery to significant cognitive and physical impairments, coma and death.

The literature reports that stroke may be responsible for a wide range of physical and emotional impairments and a significant change in the quality of life and well-being perception of the patient. However, even though the majority of the research focuses on the first three to six months post stroke when most of the functional recovery is considered to take place, ${ }^{2,30,31,32}$ it is well documented that rehabilitation continues on the long term. There is a substantial body of research, which demonstrates that with intervention, patients with chronic stroke are able to improve the performance of everyday tasks, increase the strength of the affected limbs and increase functional independence well beyond the first six months post stroke. ${ }^{33,34,35,36,37,38,40}$ Therefore, in order to maximize potential, stroke rehabilitation needs to continue long term, rather than cease in 3 months to 1 year post stroke. ${ }^{30,35}$ Affordable and supervised ongoing programs that are designed to increase the strength of the affected side and improve functional performance may not only decrease the fear of falls, decrease depression and improve the quality of life perception, but may also reduce the need for and the duration of future institutionalized care. Group exercise classes are one way to provide ongoing programs to maintain and/or improve performance after discharge from rehabilitation. 
Research shows that survivors of stroke continue to experience falls far beyond the 6 and 12 months post stroke period and have twice the risk of falling as compared to population controls. ${ }^{34,35}$ Falling may result in physical and psychological trauma, leading to a self-imposed restriction of activity. ${ }^{36}$ Reduced confidence may prevent survivors of stroke from performing ADL's, therefore, fear of falling could be a cause of future physical dependence, and fewer social contacts. ${ }^{37}$ Restricted physical activity from fear of falling may result in muscle atrophy, loss of muscular and aerobic endurance, loss of coordination, and loss of flexibility; thus, the self imposed restriction of activity may limit the risk of falling but may also contribute to further functional decline.

Minimal literature is available on survivors of chronic stroke who have been formally discharged from physical rehabilitation and limited information is available on whether participation in a regular specialized exercise program reduces the fear of falls in patients with chronic stroke.

Depression is one of the most common emotional disorders associated with major health issues including stroke. Research shows that depression has a negative effect on the recovery of physical impairment and ADL's after stroke. ${ }^{38,40}$ However, it is still unclear whether decreased functional abilities are the cause or the consequence of PSD. It is quite possible that depression may develop secondary to significant functional limitations, dependence on family and friends, social isolation and change of work status. On the other hand, depression may greatly affect one's participation in the rehabilitation process and result in decreased motivation, effort, and less functional progress. One of the most consistent observations in patients with chronic stroke is that they spend a large proportion of the day alone and inactive. ${ }^{41}$ This observation suggested that individuals 
post stroke are at high risk of becoming socially isolated and more disabled after discharge from rehabilitation. The absence of ongoing exercise or activity programs after discharge from rehabilitation may be a major oversight in stroke management, an oversight that exacerbates disability and handicap. Further, the research on the effect of physical exercise and group exercise programs on PSD has been scarce and hence there is a need to determine whether such programs could be used as an alternative way to increase social interaction and decrease depression in patients with chronic stroke.

Research demonstrates that survivors of stroke report a lower sense of well-being and are more likely to be restricted in their cognitive and physical function. ${ }^{20}$ In many cases, significant decrease in the QOL and perceived health status persists in patients independent in the ADL, but still not performing at the pre stroke functional level. However, although both physical and cognitive disabilities constrain the subjective wellbeing of community dwelling survivors of chronic stroke, social resources can moderate the adverse effects of residual disabilities. The review of the literature established that the rehabilitation value of the psychological gains in subjective perceptions should not be underestimated with disabled groups who are at the risk of functional decline. The self satisfaction and greater confidence of engaging in physical activities informally reported by all subjects may have enabled them not only to realize their own potential, but also to better accept their disability and to deal with it more effectively. ${ }^{50}$ Therefore, enhancing the support system and providing easier access to community programs and support groups could greatly benefit the patient with chronic stroke. A group exercise program could enable the individual to continue with the physical rehabilitation while at the same 
time provide the opportunity to go out in the community, form relationships and share experiences with other survivors of stroke.

In conclusion, limited literature is available on survivors of chronic stroke who have been formally discharged from physical rehabilitation and limited information is available on whether participation in a regular specialized exercise program decreases fear of falling, decreases depression and improves quality of life/health status perception in individuals with chronic stroke. The existing research examining stroke rehabilitation has not provided clear or consistent information regarding which procedures are most effective with what type of patients ${ }^{45}$ Research about falls, depression, quality of life, and self perceived health status for patients with chronic stroke are incomplete. Several researchers have discussed the need of information to identify the role of exercise and optimum levels of activity in order to increase independence in ADLs and enhance functional ability ${ }^{61}$ and hence, there is a need to determine whether a regular supervised exercise program would provide an effective physical and psychological rehabilitation for survivors of chronic stroke well beyond the first six months post the stroke onset.

It is the intent of this study to determine the effectiveness of a regular exercise group program in decreasing fear of falls, decreasing depression and improving quality of life/health status perception in community dwelling elders with chronic stroke. The results of this study would help to establish whether such an exercise program could be an effective way to improve the health status and general well-being of the community dwelling elders with chronic stroke, which would further help to establish community exercise programs as an important and necessary part of the rehabilitation of patients with chronic stroke. 


\section{CHAPTER III}

\section{METHODOLOGY}

\section{Research Hypothesis}

The principal investigator tested the following research hypothesis:

Community dwelling elders with chronic stroke who participate in a regular exercise group program will demonstrate decreased fear of falls, decreased depression and improved quality of life/health status perception as compared to community dwelling elders with chronic stroke who don't participate in such an exercise program. Subjects

Two convenience samples of 13 English- speaking community dwelling elders with chronic stroke, as defined by history of stroke $>1$ year, between 60 and 80 years old, both male and female were selected. The first group consisted of individuals who at the time of the research were participating in the Adult Fitness Group at SMH and who had been participating in this group for more than six months. The second group, which served as a control group, consisted of former SMH patients who at the time of the research were not involved in a regular exercise program and who had not been involved in a regular exercise program for at least one year prior this research. Inclusion Criteria

Subjects of the two groups were included in the study if they met the following criteria: English speaking male or female elders between 60 and 80 years old, clinical diagnosis of stroke post 1 year or more, functional status of gait/transfers with modified independence to moderate assistance with or without assistive device (as determined by score of 3 to 6 in the Functional Independence Measurement (FIM) on the hospital 
discharge form) and living at home. The subjects in the first group had to be involved in the Adult Fitness Group (AFG) at SMH for at least 6 months. The subjects in the second group were selected if they have not had participated in a regular exercise program for at least one year prior this research. All subjects were volunteers.

\section{Adult Fitness Group (AFG)}

On discharge from physical/occupational therapy, the patient is informed about the AFG by his/her therapists. In order to participate in the AFG, the individual needs to obtain a prescription from the doctor referring him/her to the exercise program. The prescription is valid for one year unless the individual is hospitalized, in which case new prescription is needed. The exercise program is usually written by the physical therapist according to the abilities and needs of the patient. This way, each participant exercises under a program, which has been specifically tailored to him/her. Currently, the AFG is supervised by the outpatient occupational therapists and the exercises are performed in the physical therapy gym at SMH. This way, there is a constant communication between the occupational and physical therapists and if needed, the exercise program can be modified on a continuous basis to better respond to the abilities of the patient. Exercise activities include treadmill, upper body ergonometer, bicycle, parallel bar exercises, balance exercises, upper extremities and lower extremities strengthening exercises and range of motion exercises. The participants can continue to participate in the program for as long as they want. The cost of the program is $\$ 60.00$ per month and the group meets two times a week for one hour each time. 
Procedures

A hospital representative selected a convenience sample of subjects for the control group using the inclusion criteria provided by the principal investigator. The hospital representative reviewed the discharge forms from the Rehabilitation Department at SMH starting with the discharges from 1/01/02 and back and selected the first 30 individuals who met the inclusion criteria. Then he contacted the individuals from the selected control group and mailed a questionnaire package consisting of four questionnaires, a cover letter/consent form and a return envelope to these individuals who agreed to participate in the research. The principal investigator contacted the individuals in the experimental group while they were waiting at SMH Physical Therapy department before their exercise class. She introduced herself to the subjects, explained the purpose of the study, read the cover letter, got consent and finally handed each individual the questionnaire package. The individuals were told to take home the questionnaire package, complete the questionnaires, and return them to the principal investigator. The individuals in the experimental group were verbally informed by the principal investigator that if an individual scores 10 or above on the GDS (score of $10-15$ indicates the presence of a severe depression), he/she will be contacted by the principal investigator and will be asked if he/she would like to be referred to the appropriate medical staff to address the issue. The individuals in both groups were also informed in writing on the above-mentioned matter through the cover letter/consent form.

Fall related self-efficacy was measured using the Falls-Efficacy scale (FES). Presence and severity of depression was assessed using the Geriatric Depression Scale (GDS) short form. Self perceived functional status was assessed with the Health 
Assessment Questionnaire (HAQ). Demographic information such as age, medical conditions, exercise frequency, and hospitalization frequency was documented for each participant. In order to avoid bias and suggestions, the names of the instruments were removed and replaced by numbers - Questionnaire \#1, Questionnaire \#2, Questionnaire \#3 and Questionnaire \#4 respectively. In addition, the individuals is the experimental group were asked to give two answers to each question, one, how they felt before involving in the Adult Fitness Group (AFG) (pre exercise) and second, how do they feel now after six or more months of participation in this program (post exercise).

The scores of the tests measuring fear of falls, depression and perceived health status of the group of individuals involved in a regular exercise program were compared to the scores of the control group to establish whether participation in such an exercise program is effective in decreasing fear of falls, decreasing depression and increasing quality of life/health status perception in elders with chronic stroke. The scores of pre and post involvement in the AFG were compared to determine whether participation in an exercise program for six ore more months would affect fear of falls, depression and health status perception in the individuals in the exercise group.

All participants were volunteers and no compensation was given to them for their participation. There was no cost to the individuals for participating in this study. There was no known risk for participation in this research. The anonymity of the participants was kept by assigning a number to each participant rather than using his/her name. 
Falls Efficacy Scale (FES) ${ }^{13,25,69}$

Although fear of falling may result in restricted level of functioning, selfreport of fear was found to be a poor predictor of actual behaviour. ${ }^{25}$ In order to achieve a more objective estimate of fear of falling in the elderly, the Falls Efficacy Scale was developed with the goal to measure fear based on the operational definition of fear as "low perceived self-efficacy or confidence at avoiding falls." ${ }^{69}$ Self-efficacy in the context of fear of falling represents " the degree of confidence a person has in performing common daily activities without falling". ${ }^{25}$ The scale was designed to measure self efficacy in 10 non hazardous activities of daily living, which were selected by physical therapists, occupational therapists, rehabilitation nurses, and physicians. The initial activities chosen by the therapists, nurses and physicians were getting dressed and undressed, getting on and off the toilet, preparing meals not requiring carrying heavy or hot objects, taking a bath or a shower, getting in and out of a chair, getting in and out of bed, answering the door or telephone, reaching into cabinets or closets, walking around the house, personal grooming, performing light housekeeping, and doing simple shopping. ${ }^{69}$ Confidence at performing the activities was based on a 10 point scale with higher number representing lower self-efficacy. The total FES score was calculated as the sum of the scores of the 10 questions and ranged from 10 to 100. Later, the scale was revised and since most individuals scored relatively high on grooming and toileting, these two activities were replaced by light housekeeping and simple shopping. The scoring was also modified with low score 
corresponding to low, rather than high, confidence. ${ }^{13}$ However, since the principal investigator felt that toileting and grooming are activities of significant importance to functional independence in the patient with chronic stroke, these two activities were kept in the FES and were used instead of light housekeeping and simple shopping.

The reliability of FES was tested several times by Tinetti and others. The scale was found to be a reliable instrument to measure self efficacy and is widely used to assess fear of falls during ADLs. ${ }^{13,25,69,70,71,72}$ FES is in the free domain and no charge or special training is required to use the scale. The scale was directly provided to the principal investigator by Dr. Mary Tinetti's office at Yale University.

Geriatric Depression Scale (GDS) ${ }^{28}$

Assessing depression in the elderly is difficult since depression may have atypical presentation in the elderly individuals. ${ }^{73}$ Depression in the geriatric population is often undiagnosed and untreated and it has been estimated that only $10 \%$ of the depressed elderly receive treatment. ${ }^{74}$ Even though there are numerous depression scales, most of them have not been originally designed for the elderly and only few of them have been validated in the geriatric population. ${ }^{73}$ Holroyd and Clayton ${ }^{73}$ reviewed the most commonly used depression scales such as the Hamilton Rating Scale for Depression, the Zung Self-Rating Depression Scale, the Montgomery-Asberg Depression Scale and the Geriatric Depression scale. The scales were reviewed for their validity (does the scale measure the symptom it is supposed to measure), reliability (are the measures consistent and 
reproducible), sensitivity (does the patient truly have the symptoms) and specificity (is the patient without symptoms accurately classified). ${ }^{73}$ The results of the study showed that by far, the GDS was the best validated instrument in various geriatrics populations.

GDS was developed specifically to discriminate depressive symptoms in the geriatric population. It is designed as a self-administered questionnaire, but can also be given in a face-to-face format. The original number of items included in the scale was 100 , but later it was decreased to 30 . A GDS short form was also developed and consisted of the 15 items in the original form that had the highest correlation with depressive symptoms. ${ }^{73}$ Each question in the scale has two answers "yes/no" and 1 point is counted for each depressive answer. The score ranges from 0 to 15 and is assessed in three scoring intervals: $0-4$ No depression; 5-10 Mild depression; and 11+ Severe depression. The GDS short form is free to use, it is easy to administer and needs no prior psychiatric knowledge. ${ }^{75,76}$ Health Assessment Questionnaire (HAQ) ${ }^{77,78,79}$

The Health Assessment Questionnaire (HAQ) was initially developed to measure self-reported functional status in many disease areas including arthritis, HIV/AIDS, and normal aging. ${ }^{77,78}$ It is a self-reported functional status instrument, which is considered to be generic, rather than disease specific, and is widely used throughout the world as a valid and reliable instrument to evaluate quality of life, resource use, costs, work force disability, morbidity, mortality, and other diverse outcomes in the patient. ${ }^{79}$ The instrument is copyrighted so that it can be used unmodified in order to preserve the validity of the results. However, 
the HAQ is in the public domain and there is no charge for using the instrument. The instrument is usually self-administered, but can also be given face-to-face, or in a telephone interview. The reliability, validity and applicability of HAQ in multiple settings and languages has been widely discussed and a complete list of the citations (in excess of 400) can be found on the Stanford University School of Medicine, Division of Immunology \& Rheumatology web page ${ }^{79}$ HAQ and instructions for use can be directly downloaded from this site along with the complete list of publications.

HAQ assesses patient outcomes in 5 domains: 1) disability, 2) discomfort and pain, 3) drug use, 4) dollar cost, and 5) death. The first two domains, which comprise the HAQ Disability Index and Pain Scale, can be used independently. ${ }^{76}$ For the purpose of this study, the domain of disability was used where disability is assessed in eight categories: 1) dressing and grooming, 2) arising, 3) eating, 4) walking, 5) hygiene, 6) reach, 7) grip, and 8) common daily activities. Each category consists of 2 to 3 questions and there is a total of 20 questions and four possible responses to each question:

Without any difficulty $=0 \quad$ With much difficulty $\quad=2$ With some difficulty $=1 \quad$ Unable to do $\quad=3$ The highest score reported by the patient for any question of the eight categories determines the score for that category. The total score is the average score of all eight categories and can range from 0 to 3 . In this research, the Alternative Disability Index scoring method was used, where the aids and devices variables are not used to calculate the Disability index. The Disability Index is a good 
predictor of future disability and costs and has been found to be reliable and valid in different languages and contexts. ${ }^{79}$

Demographics Questionnaire

The questionnaire was developed by the principal investigator and demographic, social and health related factors felt likely to be associated with fear of falls, depression, quality of life and function were selected. Demographic data included age, gender, education, and residence. Medical data included selfreported health conditions (coronary artery disease, depression, hypertension, stroke, and others), number of strokes, time since the last stroke, number of hospitalizations since the last stroke and days of hospitalization. Falls related data included self-reported number of falls in the past 6 months and reporting whether the subject is afraid to fall. Frequency of exercise in the past 1 year was documented as well as the use of assistive devices such as cane, walker, hemi walker, and wheelchair. In addition, the subjects of the first group were asked to determine if the exercise program is beneficial and if so, in which way: 1) by improving strength and endurance, 2) balance, 3) walking ability, 4) social contacts, and 5) self confidence. Both groups were asked to rate their health as either poor, fair, satisfactory, good, or excellent. 


\section{CHAPTER IV}

\section{RESULTS}

SPSS version 11 statistical package was used to analyze the data.

Demographics: 23 questionnaire packages were handed out to the individuals in the Adult Fitness Group (AFG) and $22(96 \%)$ were returned. From them, $6(27 \%)$ were excluded because the individuals did not meet the inclusion criteria ( 5 individuals did not have a history of stroke and 1 individual had a history of stroke of less than 1 year) and 2 $(9 \%)$ were excluded for statistical reasons, since their questionnaires' scores were significantly different from the scores of the rest of the individuals. From the total 13 subjects in the experimental group, 2 were women and 11 were men. The mean group age was $69.46(S D \pm 2.57)$ ranging between $65-73$ years old. 30 questionnaire packages were mailed to the individuals in the control group and $13(43 \%)$ were returned. From them, all 13 individuals meet the inclusion criteria. From the total 13 subjects in the control group, 5 were women and 8 were men. The mean group age was 70.69 (SD \pm 4.09) ranging between $63-76$ years old. (Table 1)

Both groups were similar in living conditions, ambulatory devices, medical history and number and days of hospitalization. The subjects in both groups reported a history of only 1 stroke with the exception of 1 individual of the control group who reported having more than 1 stroke. In terms of falls, both groups were similar in the number of reported falls, but more individuals (11) from the experimental group reported been afraid of falling as compared to 7 individuals in the control group. (Table 1) Of these 7 individuals, however, two had fallen in the past year. The subjects in the experimental group rated their health status perception slightly higher than the subjects in 
the control group. 11 individuals of each group rated their health as either satisfactory or good, but two individuals in the experimental group rated their health as excellent as compared to two individuals in the control group who rated it as fair.

Falls Efficacy Scale: The experimental group scored slightly higher on this scale. The mean score for this group was $80.69(\mathrm{SD} \pm 11.22)$ and ranged from 62 to 98 . (Table 2) Question \#3 (Preparing meals not requiring carrying heavy or hot objects) had the lowest mean score of 4.27 and questions \#7 (Get in and out of a chair), \#9 (Personal grooming), $\# 10$ (Get on and off the toilet), and \#4 (Walk around the house) had the highest mean scores of $9.08,9.00,8.77$ and 8.69 respectively. (Table 3 ) The mean score for the control group was $77.31(\mathrm{SD} \pm 12.45)$ and ranged from 50 to 93. (Table 2) Question \#3 (Preparing meals not requiring carrying heavy or hot objects) also had the lowest mean score of 3.69 and questions \#9 (Personal grooming), \#5 (Get in and out of bed), \#7 (Get in and out of a chair), and \#6 (Answer the door or telephone) had the highest mean scores 9.58, 9.38, 8.53 and 8.38 respectively. (Table 3 )

Geriatric Depression Scale short form: The experimental group scored lower on this scale. The mean score for the experimental group was $3.7692(\mathrm{SD} \pm 2.5217)$ and ranged from 0 to 8 . (Table 2) Depressive answers were given most frequently to questions \#2 (Have you dropped many of your activities and interests), \#13 (Do you feel full of energy), \#4 (Do you prefer to stay at home rather than going out and doing new things), and \#6 (Do you often get bored). (Table 4) The mean score for the control group was $6.3077(\mathrm{SD} \pm 2.5621)$ and ranged from 1 to 10 . (Table 2) Depressive answers were given most frequently to questions \#2 (Have you dropped many of your activities and interests), \#4 (Do you prefer to stay at home rather than going out and doing new things), 
\#13 (Do you feel full. of energy) and \# 15 (Do you think that most people are better off than you are). (Table 4)

Health Assessment Questionnaire: The experimental group scored slightly lower than the control group indicating that the individuals in the experimental group had less difficulty performing ADL than the individuals in the control group. The mean score for the experimental group was $1.3558(\mathrm{SD} \pm .6268)$ and ranged from 0 to 2.38. (Table 2) The most difficult tasks to perform were to do light chores such as vacuuming (mean score 2.4667 ), cut meat (mean score 2.0667 ), open a milk carton (mean score 1.8 ), and run errands and shop (mean score 1.6). The mean score for the control group was 1.4808 (SD \pm .6205 ) and ranged from .75 to 2.63 . (Table 2) For this group, the most difficult tasks to perform were to do light chores such as vacuuming (mean score 2.8462), open a milk carton (mean score 2.0), run errands and shop (mean score 1.7692), bend down and pick up clothing from the floor (mean score 1.5385) and cut meat (mean score 1.4615).

Correlations: Pearson correlation was used to calculate the correlations between the three variables (falls efficacy, depression, and health assessment). First, correlations were calculated using both groups as a whole and significant negative correlations were found between the falls efficacy and health assessment $(r=-.804 p<.01)$ and falls efficacy and depression $(r=-.488 p<.05)$, and a positive correlation was found between depression and health assessment $(\mathrm{r}=.524 \mathrm{p}<.01)$. (Table 5) Second, correlations were calculated for each group separately. In the experimental group, a significant negative correlation between falls efficacy and health assessment $(r=-.713 p<.01)$ was found and there were no other correlations. (Table 6) In the control group, significant negative correlations were found between the falls efficacy and health assessment $(r=-.885 p<.01)$ and falls 
efficacy and depression $(r=-.816 p<.01)$, and a positive correlation was found between depression and health assessment $(r=.718 p<.01)$. (Table 7) Third, correlations were calculated for the experimental group for the pre involvement in the Adult Fitness Group and significant negative correlations were found between the falls efficacy and health assessment $(r=-.659 p<.05)$ and falls efficacy and depression $(r=-.568 p<.05)$, and a positive correlation was found between depression and health assessment $(r=.572 \mathrm{p}<.05)$. (Table 8)

T-tests: Independent samples t-test was used to estimate the differences in the three variables (falls efficacy, depression, and health assessment) between the experimental and control group. A significant difference was found only in the depression variable $(P=.018)$ and no significant differences were found between the falls efficacy and health assessment variables. (Table 2) Paired samples t-test was used to estimate the difference between the pre and post involvement in the Adult Fitness group for the experimental group and significant differences were found for all the variables: falls efficacy $(\mathrm{P}=.007)$; depression $(\mathrm{P}=.000)$; health assessment $(\mathrm{P}=.004)$. (Table 9) 


\section{CHAPTER V}

\section{DISCUSSION AND CONCLUSION}

The major finding of this study was that a significant difference was found in the depression variable between the experimental and the control group, which suggests that the individuals who participated in the regular exercise program were less depressed than these who did not exercise. The mean score of 3.769 on the GDS in the experimental group indicates no depression in this group as a whole (score of 0-4 indicates no depression), while the mean score of 6.307 in the control group indicates mild depression in this group as a whole (a score of 5-10 indicated mild depression). A possible explanation for the decrease in depression in the experimental group could be an improvement in function, increased self-confidence and increased social interaction. As the review of literature shows, functional abilities have been strongly associated with depression. ${ }^{17}$ It is very possible that with regular exercise, balance, strength and endurance may have increased and led to improvement in function in this group (as supported by the improved score on the HAQ for post exercise involvement). Research shows that with intervention, the patient with chronic stroke can improve functional tasks such as reaching, standing, walking, and ascending/descending stairs. ${ }^{35,50}$ An improvement in strength, cardiovascular fitness and functional motor performance may have led to gains in volitional control, which in turn may have resulted in increased functional independence and decreased depression. When asked about the benefits of the exercise group program, all subjects in the experimental group, with the exception of one, indicated an improvement in either strength, endurance, balance and walking ability or an improvement in all of these areas. These findings are supported by the results found when 
comparing self reported pre and post exercise involvement of the subjects in the exercise group. The GDS mean score of 8.7692 in the pre exercise was significantly higher than the post exercise score of 3.769 indicating that prior to the initiation of the AFG, the subjects were much more depressed than post six or more months of regular exercise.

Improvement in functional status may have also led to improvement in selfesteem, which may also be a possible explanation for the decrease in depression in the experimental group. Research has found that with exercise, psychological gains in subjective perceptions should not be underestimated and self-satisfaction and greater confidence may enable the individuals with chronic stroke to realize their own potential and to accept their disability better. ${ }^{50}$ Therefore, improved self-acceptance and selfconfidence/esteem may have also been a factor in decreasing depression in the individuals in the experimental group. This may be supported by the result that 12 out of the 13 individuals in the experimental group indicated improved self-esteem as a benefit of participation in the exercise program.

Increased social interaction secondary to engaging in a group exercise may have also led to a decrease in depression. As research indicates, most patients with chronic stroke are relegated to an inherently sedentary lifestyle and social isolation. $41,43,44$ Participation in an exercise group program, where the majority of the individuals have a history of stroke, may have also served as a support group where the participants and their caregivers could share experiences. Because the experience of others as well as one's own experience may influence confidence ${ }^{13}$, exposure to others with similar impairments may influence motivation, improve participation and increase selfconfidence in engaging in social contacts, therefore reducing social isolation and 
decreasing depression. The review of literature demonstrates that subjective appreciation of the exercise program, enjoyment and socialization may also contribute to positive psychological gains in the patient with chronic stroke. ${ }^{11}$ Increased socialization was also indicated as a benefit of the group exercise program by 8 individuals. Therefore, decrease in depression may be a significant benefit of participation in a regular exercise program to the survivors of chronic stroke.

The results of this study did not find significant difference in the falls-efficacy and health assessment variables. However, the small sample size may have affected the results of this assessment. When the mean score of the FES of the experimental group (80.69) is compared to the score of the control group (77.31), it could be seen that the experimental group scored higher, which indicates increased confidence in functional activities. The same is valid for the HAQ score, where the experimental group score (1.3558) is lower than the score of the control group(1.4808), thus indicating decreased difficulty of performing functional tasks. Further, even though the t-test did not indicate a significant difference between the groups in these two variables, a significant correlation was found between all three variables for both groups as a whole. A negative correlation between depression and self-efficacy $(r-488 p<.05)$ indicates that as depression decreases, people feel more confident that they will not fall. A positive correlation between depression and health assessment $(\mathrm{r} .524 \mathrm{p}<.01)$ indicates that as depression decreases, people have less difficulty when performing functional activities and rate their health status/quality of life higher. A negative correlation between falls efficacy and health assessment $(\mathrm{r}-.885 \mathrm{p}<.01)$ indicates that as confidence increases, people have less difficulty with daily activities. These results demonstrate that there is a relationship 
between the variables and it may be possible that with increased sample size there may be a difference between the falls- efficacy and health assessment variables as well. This possibility may be supported by the subjective appreciation of the program by all 13 individuals in the exercise group, all of whom rated the program as beneficial and who also rated their health higher than the control group.

Fall-efficacy is shown to be influenced by the presence of relevant skills (gait, getting up, etc), past experiences and depression. ${ }^{23}$ Therefore, the ability to perform certain functional activities, may to a large extent affect the fall-efficacy (confidence) of the patient with chronic stroke. This study showed no significant difference in the falls efficacy variable between the groups even though the experimental group scored higher on the FES then the control group. However, such a result may have been influenced by a couple of factors. First, there was no information on the base functional level upon discharge from physical therapy in the experimental group. Therefore, it may be quite possible that the exercise group had a lower functional base at time of discharge and the initiation of the exercise program. Second, the investigator was not able to obtain information on the type of stroke and lesion location in each subject, hence, it was impossible to control for the extent of pathology. Therefore, it could have been possible that the subjects in the experimental group were specifically referred to the exercise program because they had more impairments and less functional ability then the subjects in the control group. Thus, if any, the gains in functional tasks performance and changes in the falls-efficacy may have not been adequately estimated by comparing this group to the control group. Therefore, the benefits of the exercise program in influencing the fallsefficacy in the patient with chronic stroke may have been underestimated. The benefit of 
engaging in a regular exercise program in increasing falls efficacy, however, is supported by the results found when comparing pre and post involvement in the AFG for the subjects in the experimental group. The significant difference found between the scores of FES indicate that there was a significant increase in the confidence of performing functional tasks for this group. Thus, it is very likely that the improvement in strength, balance, gait and transfers has led to increase in skills and hence to increased confidence and less fear of falls when performing ADLs.

In similar fashion, the health assessment/quality of life variable may have also been underestimated. While falls efficacy measures confidence in performing functional tasks, health assessment measures degree of difficulty when performing functional activities. Therefore, the skill and ability to perform a particular task may have influenced the scores on the HAQ as well. Selecting a larger sample size and controlling for impairments may have been a more adequate way to estimate the benefits of such a program. Even though no difference was found between the experimental and control group in the health assessment variable, there was a significant difference between the pre and post involvement in the exercise program for the first group. The results demonstrate that there was a significant decrease in the HAQ score post exercising for six or more months, thus indicating significant decrease in difficulty when performing functional activities. This finding supports the possibility that through exercise, improved mobility and gait may have resulted in increased mastery of task specific activities and therefore in decrease of difficulty with ADLs and increased quality of life perception.

The results of this study show that participation in a regular exercise program decreases depression in the community dwelling elders with chronic stroke. The lack of 
significant difference between the two groups in the falls-efficacy and health assessment variables is due most likely to the small sample size, to the inability to control for the location and size of the brain lesion and the different degree of the neurological impairments, which in turn influence the level of mobility and functional status of the subjects. This study, regardless of the small sample size, demonstrates that participation in a regular exercise group program has a positive effect on decreasing depression in the community dwelling elders with chronic stroke and that there is a relationship between falls-efficacy, depression and health status/quality of life. Since no difference was found between the experimental and control group, but a significant difference was found for pre and post exercise involvement in the experimental group when comparing falls efficacy and health assessment variables, the results on fear of falls and quality of life in this study are inconclusive. Further research is needed to determine whether participation in a regular exercise program can affect fear of falling and health assessment/quality of life perception in community dwelling elders with chronic stroke. The results of this research, however, contribute to enhance the information on survivors of chronic stroke, who have been formally discharged from rehabilitation and should be continued to further establish the effects of a regular exercise program on the general well-being of the patient with chronic stroke.

The results of this research were not only significant to demonstrate that participation in a regular exercise program is associated with decreased depression in elders with chronic stroke, but also to show that physical exercise can lead to positive psychological gains in the medically compromised elders. Thus, this research 
demonstrates that physical exercise can affect the emotional well being of the individuals and not be limited to improvements in the musculoskeletal system.

The major implication of this research to the field of physical therapy is that it demonstrates that a regular exercise program may provide the opportunity to successfully continue with rehabilitation post formal discharge from physical therapy. A significant drawback of the current health care is that rehabilitation for the patient with chronic stroke stops with formal discharge from the hospital/physical therapy and no opportunity is provided to continue with supervised rehabilitation post this discharge. Since survivors of stroke may be more medically compromised that the general population, an exercise program supervised by trained therapists may be the optimum way to safely and effectively continue with rehabilitation. Such a program will also provide the opportunity to refer the patients with chronic stroke to a program that is specifically designed to their particular needs and functional abilities.

There are limitations to this study. First, the major limitation of this study was the small sample size and, therefore, there may have been an inadequate power to detect associations with the instruments scores. Since the experimental group involved only the participants in the Adult Fitness Group at SMH, the size of this group was self-limiting to the number of willing subjects with a history of chronic stroke. The small sample size of the control group may have been due to the data collection procedure where the questionnaire packages were mailed, rather than handed to the subjects, thus decreasing the number of the responses. Second, the research was limited to subjects who were willing to volunteer and, therefore, they were a self-selected group of willing and motivated individuals. The volunteer subjects may have been less likely to have 
significant impairments and suffer from self-imposed restriction than the general population of survivors of stroke. Therefore, their functional status may have not reflected the general functional abilities of the population of elders with chronic stroke as a whole and generalizations about this population should be made with caution. Third, another limitation factor was the inability to control for the great variability of disabilities and impairments between the two groups, which may have been due to the different locations of the brain lesions, different social, emotional, economic and family support status. Since the AFG is open to all individuals, no information was available on why some individuals became involved with the program and the others did not. Perhaps greater family support and financial ability to participate in the program could have been additional confounding factors in this research. In addition, the researcher relied on selfreport for all information, without the means to objectively verify the responses given, which may have affected the generalizability of the present findings to the whole chronic stroke population.

Conclusion

Participation in a regular exercise program could be an effective way to decrease depression in community dwelling elders with chronic stroke. The relationship between fear of falls and quality of life in this research is inconclusive. Further research is needed to establish whether regular exercise can help to decrease fear of falls and increase quality of life in elders with chronic stroke. 
TABLES 
Table 1. Demographic characteristics for the experimental and control groups*

\begin{tabular}{|c|c|c|}
\hline Characteristic & $\begin{array}{c}\text { Experimental } \\
\text { Group } \\
\mathrm{n}=13 \\
\end{array}$ & $\begin{array}{c}\text { Control Group } \\
n=13\end{array}$ \\
\hline Age, mean (SD) & $69.46(\mathrm{SD}+2.57)$ & $70.69(\mathrm{SD}+4.09)$ \\
\hline \multicolumn{3}{|l|}{ Gender } \\
\hline Male & 11 & 8 \\
\hline Female & 2 & 5 \\
\hline \multicolumn{3}{|l|}{ Education } \\
\hline High School & 3 & 5 \\
\hline College & 4 & 3 \\
\hline Some graduate school & 1 & 1 \\
\hline Graduate school & 5 & 4 \\
\hline \multicolumn{3}{|l|}{ Living condition } \\
\hline Alone & & 1 \\
\hline With husband/wife & 11 & 9 \\
\hline With children & 1 & 3 \\
\hline \multicolumn{3}{|l|}{ Health conditions } \\
\hline Stroke only & 4 & 6 \\
\hline Stroke/Hypertension & 4 & 5 \\
\hline Stroke/Depression & 3 & \\
\hline Stroke/Others & 2 & \\
\hline \multicolumn{3}{|l|}{ Stroke/Depression/Hypertension } \\
\hline $\begin{array}{c}\text { Number of strokes } \\
\text { One } \\
\text { More }\end{array}$ & 13 & $\begin{array}{c}12 \\
1\end{array}$ \\
\hline \multicolumn{3}{|l|}{ Afraid of falling } \\
\hline Yes & 11 & 6 \\
\hline No & 2 & 7 \\
\hline \multicolumn{3}{|l|}{ Number of falls in the past 6 months } \\
\hline One & 7 & 4 \\
\hline Two & 2 & 2 \\
\hline More & & 1 \\
\hline No falls & 4 & 6 \\
\hline \multicolumn{3}{|l|}{ Health status perception } \\
\hline Fair & & 2 \\
\hline Satisfactory & 4 & 4 \\
\hline Good & 7 & 7 \\
\hline Excellent & 2 & \\
\hline \multicolumn{3}{|l|}{ Assistive device } \\
\hline Cane & 7 & 3 \\
\hline Walker/hemi walker & 1 & 2 \\
\hline Walker/Wheelchair & & 3 \\
\hline Cane/Wheelchair & 2 & 3 \\
\hline None & 3 & 2 \\
\hline
\end{tabular}

* Values are number unless otherwise indicated. 
Table 2. Mean, minimum-maximum and difference (independent samples t-test) in the instrument scores for the experimental (post-exercise enrollment) and control groups*

\begin{tabular}{|l|c|c|c|}
\hline $\begin{array}{l}\text { Instrument } \\
\text { Mean (SD) } \\
\text { Minimum-maximum }\end{array}$ & $\begin{array}{c}\text { Experimental } \\
\text { group } \\
\mathrm{n}=13\end{array}$ & $\begin{array}{c}\text { Control } \\
\text { group } \\
\mathrm{n}=13\end{array}$ & $\begin{array}{c}\text { Independent } \\
\text { samples } \\
\text { T-test }\end{array}$ \\
\hline FES & $80.69( \pm 11.22)$ & $77.31( \pm 12.45)$ & .474 \\
& $62.00-98.00$ & $50.00-93.00$ & \\
\hline GDS & $3.77( \pm 2.52)$ & $6.31( \pm 2.56)$ & .018 \\
& $.00-8.00$ & $1.00-10.00$ & \\
\hline HAQ & $1.36( \pm .63)$ & $1.48( \pm .62)$ & .614 \\
& $.00-2.38$ & $.75-2.63$ & \\
\hline
\end{tabular}

* FES indicates Falls efficacy Scale; GDS indicates Geriatric Depression Scale short form; HAQ indicates Health Assessment Questionnaire. 
Table 3. Mean (SD) and median for FES for the experimental (post-exercise enrollment) and control groups*

\begin{tabular}{|l|c|c|}
\hline Question, mean (SD), median & $\begin{array}{c}\text { Experimental } \\
\text { group }\end{array}$ & Control group \\
\hline 1. Take a bath or a shower. & $7.62( \pm 1.50), 8$ & $7.15( \pm 1.77), 8$ \\
\hline 2. Reach into cabinets. & $8.62( \pm 1.33), 9$ & $7.31( \pm 1.65), 8$ \\
\hline 3. Prepare meals not requiring carrying heavy & $4.62( \pm 2.93), 4$ & $3.69( \pm 2.21), 3$ \\
\hline or hot objects. & & \\
\hline 4. Walk around the house. & $8.69( \pm 1.49), 9$ & $7.69( \pm 1.03), 8$ \\
\hline 5. Get in and out of bed. & $8.46( \pm 1.85), 9$ & $9.38( \pm .77), 10$ \\
\hline 6. Answer the door or telephone. & $7.92( \pm 2.47), 9$ & $8.38( \pm 2.04), 9$ \\
\hline 7. Get in and out of a chair. & $9.08( \pm .95), 9$ & $8.54( \pm 1.05), 9$ \\
\hline 8. Get dressed and undressed. & $7.92( \pm 2.10), 9$ & $8.15( \pm 2.04), 9$ \\
\hline 9. Personal grooming. & $9.00( \pm 1.16), 9$ & $9.54( \pm .88), 10$ \\
\hline 10. Get out and off the toilet without falling. & $8.77( \pm 1.30), 9$ & $7.46( \pm 1.51), 8$ \\
\hline Total & $80.69( \pm 11.22)$ & $77.31( \pm 12.45)$ \\
\hline
\end{tabular}


Table 4. Mean (SD) and median for GDS for the experimental (post-exercise enrollment) and control groups*

\begin{tabular}{|c|c|c|}
\hline Question, mean (SD), median & $\begin{array}{l}\text { Experimental } \\
\text { group } \\
n=13\end{array}$ & $\begin{array}{l}\text { Control group } \\
\qquad \mathrm{n}=13\end{array}$ \\
\hline 1.Are you basically satisfied with your life? & $.31( \pm .48), 0$ & $.38( \pm .51), 0$ \\
\hline 2.Have you dropped many of your activities? & $.62( \pm .5), 1$ & $1( \pm 0)$ \\
\hline 3. Do you feel happy most of the time? & $.15( \pm .38), 0$ & $.38( \pm .51), 0$ \\
\hline $\begin{array}{l}\text { 4.Do you prefer to stay at home rather going out and doing } \\
\text { new things? }\end{array}$ & $.54( \pm .52), 1$ & $.85( \pm .38), 1$ \\
\hline 5.Do you feel life is empty? & $0( \pm 0), 0$ & $0( \pm 0)$ \\
\hline 6. Do you often get bored? & $.54( \pm .52), 1$ & $.46( \pm .52), 0$ \\
\hline 7. Are you in good spirits most of the time? & $0( \pm 0), 0$ & $0( \pm 0)$ \\
\hline $\begin{array}{l}\text { 8. Are you afraid that something bad is going to happen to } \\
\text { you? }\end{array}$ & $.15( \pm .38), 0$ & $.31( \pm .48), 0$ \\
\hline 9. Do you feel helpless? & $.08( \pm .28), 0$ & $\begin{array}{l}7.69 \mathrm{E}-02 \\
( \pm .28), 0\end{array}$ \\
\hline $\begin{array}{l}\text { 10. Do you feel that you have more problems with memory } \\
\text { than most? }\end{array}$ & $.15( \pm .38), 0$ & $.23( \pm .44), 0$ \\
\hline 11. Do you think that is wonderful to be alive? & $.08( \pm .28), 0$ & $.15( \pm .38), 0$ \\
\hline 12. Do you feel pretty worthless the way you are now? & $.15( \pm .38), 0$ & $.38( \pm .51), 0$ \\
\hline 13. Do you feel full of energy? & $.62( \pm .51), 1$ & $.85( \pm .38), 1$ \\
\hline 14. Do you feel that your situation is hopeless? & $.23( \pm .44), 0$ & $.38( \pm .51), 0$ \\
\hline $\begin{array}{l}\text { 15. Do you think that most people are better off than you } \\
\text { are? }\end{array}$ & $.15( \pm .38), 0$ & $.85( \pm .38), 1$ \\
\hline Total & $3.77( \pm 2.52)$ & $6.31( \pm 2.56)$ \\
\hline
\end{tabular}

*GDS indicates Geriatric Depression Scale short form. 
Table 5. Correlations between falls efficacy, depression and health perception for both groups as a whole using Pearson correlation*

\begin{tabular}{lccc}
\hline $\begin{array}{l}\text { Instrument } \\
\mathrm{n}=26\end{array}$ & FES & GDS & HAQ \\
\hline FES & 1.000 & & \\
\hline GDS & $-.488(\dagger)$ & 1.000 & \\
\hline HAQ & $-.804(\ddagger)$ & $.524(\ddagger)$ & 1.000 \\
\hline
\end{tabular}

* FES indicates Falls efficacy Scale; GDS indicates Geriatric Depression Scale short form, HAQ indicates Health Assessment Questionnaire.

$\uparrow$ Correlation is significant at the 0.05 level (2-tailed).

$\ddagger$ Correlation is significant at the 0.01 level (2-tailed).

Table 6. Correlations between falls efficacy, depression and health perception for the experimental group for post-exercise enrollment using Pearson correlation*

\begin{tabular}{lccc}
\hline $\begin{array}{l}\text { Instrument } \\
\mathrm{n}=26\end{array}$ & Post-FES & Post-GDS & Post-HAQ \\
\hline Post-FES & 1.000 & & \\
\hline Post-GDS & -.100 & 1.000 & \\
\hline Post-HAQ & $-.713(\dagger)$ & .359 & 1.000 \\
\hline
\end{tabular}

* Post-FES indicates post-exercise enroliment Falls efficacy Scale; HAQ indicates post-exercise enroliment Health Assessment Questionnaire

+ Correlation is significant at the 0.01 level (2-tailed). 
Table 7. Correlations between falls efficacy, depression and health perception for the control group*

\begin{tabular}{lcc}
\hline Instrument & GDS & HAQ \\
\hline FES & & \\
Pearson correlation & $-.816(\dagger)$ & $-.885(\dagger)$ \\
Sig. (2-tailed) & .001 & .000 \\
$\mathrm{n}$ & 13 & 13 \\
\hline GDS & & \\
Pearson correlation & 1.000 & $.718(\dagger)$ \\
Sig. (2-tailed) &. & 0.006 \\
$\mathrm{n}$ & 13 & 13 \\
\hline
\end{tabular}

* FES indicates Falls efficacy Scale; GDS indicates Geriatric Depression Scale short form; HAQ indicates Health Assessment Questionnaire.

† Correlation is significant at the 0.01 level (2-tailed).

Table 8. Correlations between falls efficacy, depression and health perception for the experimental group for pre-exercise enrollment using Pearson correlation*

\begin{tabular}{lcc}
\hline Instrument & Pre-GDS & Pre-HAQ \\
\hline Pre-FES & & \\
Pearson correlation & $-.568(\dagger)$ & $-.659(\dagger)$ \\
Sig. (2-tailed) & .043 & .014 \\
$\mathrm{n}$ & 13 & 13 \\
\hline Pre-GDS & & \\
Pearson correlation & 1.000 & $.572(\dagger)$ \\
Sig. (2-tailed) &. & 0.041 \\
$\mathrm{n}$ & 13 & 13 \\
\hline
\end{tabular}

* Pre-FES indicates pre-exercise enrollment Falls efficacy Scale; Pre-GDS indicates pre-exercise enrollment Geriatric Depression Scale short form; Pre-HAQ indicates pre-exercise enrollment Health Assessment Questionnaire.

$\uparrow$ Correlation is significant at the 0.05 level (2-tailed).

$\$$ Correlation is significant at the 0.01 level ( 2 -tailed). 
Table 9. Mean, minimum-maximum and difference (paired samples t-test) in instrument scores for the experimental group for pre- and post- exercise group enrollment*

\begin{tabular}{|l|c|c|c|}
\hline $\begin{array}{l}\text { Instrument } \\
\text { Mean (SD) } \\
\text { Minimum-maximum }\end{array}$ & $\begin{array}{c}\text { Pre-exercise } \\
\text { enrollment } \\
\mathrm{n}=13\end{array}$ & $\begin{array}{c}\text { Post-exercise } \\
\text { enrollment } \\
\mathrm{n}=13\end{array}$ & $\begin{array}{c}\text { Paired } \\
\text { samples } \\
\text { T-test }\end{array}$ \\
\hline FES & $66.85( \pm 11.63)$ & $80.69( \pm 11.22)$ & .007 \\
& $40.00-85.00$ & $62.00-98.00$ & \\
\hline GDS & $8.77( \pm 5.00)$ & $3.77( \pm 2.52)$ & .000 \\
& $.00-15.00$ & $.00-8.00$ & \\
\hline HAQ & $1.93( \pm .52)$ & $1.36( \pm .63)$ & .004 \\
& $.75-2.75$ & $.00-2.38$ & \\
\hline
\end{tabular}

* FES indicates Falls efficacy Scale; GDS indicates Geriatric Depression Scale short form; HAQ indicates Health Assessment Questionnaire. 


\section{REFERENCES}

1. Fang J, Alderman M. Trend of stroke hospitalization, United States, 1988-1997. Stroke. October, 2001:2221-2225.

2. Brandstater ME. An overview of stroke rehabilitation. Stroke. November, 1999: 213(suppl II):II-40-II-42.

3. Chips E, Clainin N, Campbell V. Cerebrovascular accident. In D. Ladig \& S. Adkisson (Eds.), Neurologic disorders: Mosby's clinical nursing series. St. Louis,Missouri: Mosby-Year Book, Inc.1992:68-62.

4. Wood-Dauphine $\mathrm{S}$. The epidemiology of stroke: relevance for physical therapists. Physiother Can. 1985;37:377-86.

5. Howard G, Howard V, Katholi C, Oli M K, Huston S. Decline in US stroke mortality, an analysis of temporal patterns by sex, race and geographical region. Stroke. October, 2001:2213-2218.

6. Jamrozik K, Broadhurst R, Anderson C, Stewart-Wynne E. The role of lifestyle factors in the etiology of stroke. Stroke. 1994;25(1):51-58.

7. Nyberg L, Gustavson Y. Patient falls in stroke rehabilitation. Stroke. $1995 ; 26: 838-42$.

8. Evans RL, Haselkorn JK, Bishop DS, Hendrics RD. Characteristics of hospital patients receiving medical rehabilitation: An exploratory outcome comparison. Archives of Physical Medicine and rehabilitation. 1991;72(9):685-689.

9. Bagg S, Pombo A, Hopman W. Effect of age on function outcomes after stroke rehabilitation. Stroke. 2002;33:179-185.

10. Ozdemir F, Birtone M.,Tabatabaei R,Kokino S. Comparing stroke rehabilitation outcomes between acute inpatient and nonintense home settings. Arch Phys Med Rehabil. October, 2001;8:1375 - 1378.

11. Jorgensen L, Engstad T, Jacobsen B. Higher incidence of falls in long-term stroke survivors than in population controls. Stroke. 2002;33:542-547.

12. Hydman D, Ashburn A, Stack E. Falls events among people with stroke living in the community. Circumstances of falls and characteristic of fallers. Arch Phys Med Rehabil. 2002;83:165-170.

13. Tinetti ME, Powell L. Fear of falling and low self-efficacy: a cause of dependence in elderly. $J$ Gerontol.1999;33:4835-4838. 
14. Gianotti, G; Marra C. Determinants and consequences of post-stroke depression. Lippincott: Williams \& Wilkins, Inc; 2002;15(1):85-89.

15. Robinson RG. The clinical neuropsychiatry of stroke. New York: Cambridge University Press; 1998.

16. Parikh RM, Robinson RG, Lipsey JR. The impact of post-stroke depression on recovery in activities of daily living over two-year follow-up. Arch Neurol.1990; 47:785-789.

17. Morris PL, Robinson RG, Andrzejewski G. Association of depression with 10 year post stroke mortality. Am.J Psych.1993;150:124-129.

18. Aben I, Denollet J, Lousberg R. Personality and vulnerability to depression in stroke patients. A 1 year prospective follow-up study. American Heart Association Inc. 2002;33(10):2391-2395.

19. House A, Knapp P, Bamford J, Vail A. Mortality at 12 and 24 months after stroke may be associated with depressive symptoms at 1 month. American Heart Association Inc. 2001;32(3):696-701.

20. Clarke PH, Marshall V, Black SE, Colantonio A. Well-being after stroke in Canadian seniors: Findins from the Canadian study of health and aging. American Heart Association. 2002; 33(4):1016-1021.

21. Carod-Artal J, Egido JA, Gonzalez JL, De Seijas EV. American Heart Association, Inc.2000;31(12):2995-3000.

22. Rubinstein LZ. Quality indicators for the management and prevention of falls and morbidity problems in vulnerable elders. Annals of internal medicine.(C) 2001; 135 (part 2) supplement: 686-693.

23. Tinetti ME, Rihman D, Powel L. Falls efficacy as a measure of fear of falling. $J$ Gerontol Psych Sci.1990;45:239-43.

24. Johnson M, Cusick AB, Chang S. Home screen: A short scale to measure fall risk in the home. Blackwell Science Ltd. 2001;18(3):169-177.

25. Tinetti ME, Mendes de Leon CF, Doucette JT ,Backer D. Fear of falling and fall related efficacy in relationship to functioning among community-living elders. $J$ of Gerontology. 1994;49(3):140-147.

26. WHOQOL Group. Development of the World Health Organization WHOQOLBREF quality of life assessment. Psyhol Medicine. 1998;28:551-558. 
27. Bonita R, Solomon N, Broad J. Prevalence of stroke and stroke related disability: estimates from the Aukland stroke studies. Stroke.1997;1898-1902.

28. Sacco RL. Risk factors, outcomes, and stroke subtypes for ischemic stroke. Neurology.1997;49(suppl 4):39-44.

29. Umpred D A. Neurological Rehabilitation, Third edition. St Louis: Mosby-Year Book, Inc; 1995.

30. Wade DT, Wood VA, Hever RL. Use of hospital resources by acute stroke patients. JR Coll Physicians Lond. 1985;19:48-52.

31. Duncan PW. Synthesis of intervention trials to improve motor recovery following stroke. Top Stroke Rehabil.1997;3:1-20.

32. Kelly-Hayes M, Wolf PA, Kase CS. Time course of functional recovery after stroke: The Framingham study. J Neurol Rehabil.1989;3:65-70.

33. Werner R, Kessler S. Effectiveness of an intensive outpatient rehabilitation program for post acute stroke patients. Am J Phys Med Rehabil. 1996;74:114-120.

34. Rodriquez AA, Black PO, Kile KA, Sherman J, Stellberg B. Gait training efficacy using a home based practice model in chronic hemiplegia. Arch Phys Med Rehabil.1996;77:891-895.

35. Dean C, Richards CL, Malouin F. Task related circuit training improves performance of locomotor tasks in chronic stroke. A randomized controlled pilot trial. Arch Phys Med Rehab. 2000;81:409-417.

36. Tangeman P, Banaitis D, Williams A . Rehabilitation for chronic stroke patients, changes in functional performance. Arch Phys Med Rehabil. 1990;71:876-880.

37. Taub E, Miller NE, Novack TA, Cook EW, Fleming WC, Nepomuceno CS. Technique to improve chronic motor deficit after stroke. Arch Phys Med Rehabil. 1993;74:347-354.

38. Yekuetiel M, Guttman E. A controlled trial of retraining of the sensory function on the hand in stroke patients. Am J Phys Med Rehabil.1996;56:241-244.

39. Robertson MC, Devlin N, Gardner MM, Campbell AJ. Effectiveness and economic evaluation of a nurse delivered home exercise program to prevent falls. British Medical Journal. 2001;322:697-701.

40. Carr JH, Shepherd RB. Neurological rehabilitation. Optimizing motor performance. Oxford: Butterworth Heinemann; 1998. 
41. Tinson DJ. How stroke patients spend their days: an observational study of the treatment regime offered to patients in hospital with movement disorders following stroke. Disabil Studies. 1989;11:45-49.

42. Belmont I, Benjamin H, Ambrose J, Restuccia RD. Effect of cerebral damage on motivation in rehabilitation. Arch Phys Med Rehabil. 1969;50:507-511.

43. Lerner-Frankiel MB, Vargas S, Brown MB, Krussell K, Schoneberger W. Functional community ambulation: what are your criteria? Clin Manage. $1990 ; 6: 12-17$.

44. Hill K, Ellis P, Bernhard J, Maggs P, Hull S. Balance and mobility outcomes for stroke patients: a comprehensive audit. Aust J Physiother. 1997;43:173-180.

45. Ottenbacher KJ, Jarnell $\mathrm{S}$. The results of clinical trials in stroke rehabilitation research. Arch Neurol. 1993;50:37-44.

46. Smith GV, Silver KHC, Goldberg AP, Macko RF. Task-oriented exercise improves hamstring strength and spastic reflexes in chronic stroke patients. Stroke. 1999;30:2112-2118.

47. Matyas TA, Ottenbacher KJ. Confounds of insensitivity and blind luck: statistical conclusions validity in stroke rehabilitation clinical trials. Arch Phys Med Rehabil. 1993;74:559-565.

48. Macko RF, De Souza CA, Tretter L, Silver KH, Smith GV, Anderson PA. Treadmill aerobic exercise training reduces the energy expenditure and cardiovascular demands of hemiparetic gait in chronic stroke patients: a preliminary report. Stroke. 1997;26:28-39.

49. Texeira-Salmela LF, Olney SJ, Nadeau S. Muscle strengthening and physical conditioning to reduce impairment and disability in chronic stroke survivors. Arch Phys Med Rehab. 2000;80:1211-1218.

50. Brinkmann J, Hoskins T. Physical conditioning and altered self-concept in rehabilitated hemiplegic patients. Phys Ther.1979;59:859-865.

51. Hermann N, Black SE, Lawrence J. The Sunybrook stroke study: a prospective study of depressive symptoms and functional outcome. Stroke. 1998;29:618-624.

52. Agrell B, Dehlin O. Comparison of six depression rating scales in geriatrics stroke patients. Stroke.1989;20:1190-1194.

53. Rawsky, E. Review of the literature on falls among elderly. 1998, Sigma, Theta Tau International. 1998;30(1):47-52. 
54. Cheng PT, Wu SH, Liaw MY, Wong A, Tang FT. Symmetrical body weight distribution training in stroke patients and its effect on fall prevention. Archives of Physical Medical Rehabilitation. 2001; 82:1650-1654.

55. Vellas B, Cayala F, BocquetH, De Pemille F, Albarede JL. Prospective study of restriction of activity in old people after falls. Age Ageing. 1987;16:189-93.

56. Puisieux F, Pollez Br, Deplanque D. Successes and setbacks of the falls consultation: report on the first 150 patients. Lippincott Williams \& Wilkins, Inc. 2001;80(12):909-915.

57. Tinetti ME, Baker DI, McAvay G, Claus EB, Garrett P. A multifactorial intervention to reduce the risk of falling among elderly people living in the community. N Engl J Med. 1994;331:821-827.

58. Wolf SL, Barnhart HX, Kutner NG, McNeely E, Coogler C, Xu T. Reducing frailty and falls in older persons: an investigation of Tai Chi and computerized balance training. Atlanta FICSIT Group. Frailty and injuries: Cooperative Studies of intervention techniques. $J$ Am Geriatr Soc.1996;44:489-497.

59. Cambell AJ, Robertson MC, Gardner MM, Norton RN. Randomized controlled trial of a general practice program of home based exercise to prevent falls in elderly women. British Medical Journal.1997;315:1065-1069.

60. Campbel AJ, Robertson MC, Gardner MM, Norton RN,Tyliard MW, Buchner DM. Randomized controlled trial of a general practice program used exercise to prevent falls in elderly women. British Medical Journal. 1997; 315:1065-1069.

61. Overstal P. Falls after strokes. British Medical Journal. 1955;311:74-75.

62. Anderson E, Anderson TR, Kottke FJ. Stroke rehabilitation. Maintenance of achieved gains. Arch Phys Med Rehabil.1997;58:345-352.

63. Watkins, C, Daniels L, Jack C. Accuracy of a single question in screening for depression in a cohort of patents after stroke: comparative study. British Medical Journal. 2001;323;1159.

64. Buck D, Jacoby A, Massey A, Ford G. Evaluation of Measures to Assess Quality of Life After Stroke. American Heart Association, Inc. 2000; 31(8):2004-2010.

65. King R Quality of life after stroke. American Heart Association, Inc. 1996;27 (9): $1457-1472$. 
66. Kim P, Warren S, Madill H, Hadley M. Quality of life of stroke survivors. Qual Life Res. 1999;8:293-301.

67. Glass T, Matchar D, Belyea M, Feusner JR. Impact of social support on outcome in first stroke. Stroke. 1993;24:64-70.

68. Wyller TB, Holmen J, Laake K. Correlates of subjective well- being in stroke patients. Stroke. 1998;29:363-367.

69. Tinetti ME, Richman D, Powell L. Falls Efficacy as a Measure of Fear of Falling. $J$ of Gerontology. 1990; 45(6): 239-243.

70. Peterson E, Howland J, Kielhofner G. Falls self-efficacy and occupational adaptation among elders. Physical and Occupational Therapy in Geriatrics. 1999;16:1-17.

71. Benson C, Lusardi P. Neurological antecedents to patient falls. J Neurosci Nurs. 1995;27:331-337.

72. Petrella R J, Payne M, Myers A T, Overend B. Physical Function and Fear of Falling After Hip Fracture Rehabilitation in the Elderly. Lippincott Williams \& Wilkins, Inc. March/April, 2000;79(2):154-160.

73. Holroyd, Clayton AH. Measuring depression in the elderly: Which scale is best? Medscape General Medicine. [serial on line]. 2000. 2(4).Available at: http://www.medscape.com/viewarticle/430554.

74. Friedhoff AJ. Consensus development conference statement - diagnosis and treatment of depression in late life. In: Holroyd, Clayton AH. Measuring depression in the elderly: Which scale is best? Medscape General Medicine. 2000 Medscape http://www.medscape.com/viewarticle/430554.

75. Van-Marwijk HW, Wallace P, De-Bock GH, Hermans J, Kaptein AA, Mulder JD. Evaluation of the feasibility, realibility and diagnostic value of shortened versions of the Geriatric Depression Scale. Br J Gen Pract. 1995 April;45(393):195-199.

76. Neal RM, Baldwin RC. Screening for Anxiety and Depression in Elderly Medical Outpatients. Age-Ageing. November, 1994; 23(6):461-464.

77. Ramey DR, Fries G. in B.Spilker Quality of life and Pharmacoleconomics in Clinical Trials, $2^{\text {nd }}$ ed., The Health assessment Questionnaire 1995 - Status and review. Philadelphia: Lippincott-Raven Pub.1996, 227-237. 
78. Fries JF,Spitz P, Kraines G, Holman H. Measurement of Patient outcome in arthritis. Arthritis and Rheumatism. 1980;23:137-145.

79. Health Assessment Questionnaire. Stanford University School of Medicine, Division of Immunology \& Rheumatology. Available at: http://aramis.stanford.edu/HAQ.html. 
APPENDICES 
APPENDIX A - CONSENT FORM/COVER LETTER 


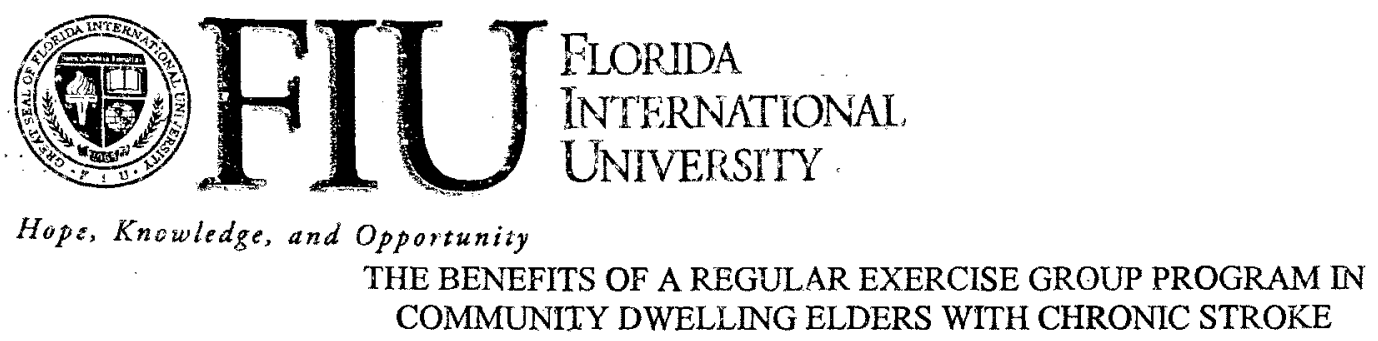

RESEARCH SUBJECT INFORMATION AND CONSENNT FORM

Dear Participant,

The purpose of this research is to investigate whether community dwelling elders with chronic stroke who participate in a regular excrcise group program demonstrate decreased fear of falls, depression and improved health stanus perception as compared to community dwelling elders with chronic stroke who don't participate in such a program. The research will be conducted by Dessislava Dakova, PT, physical therapist at South Miami Hospital and graduate student at Florida International University.

Your participation will require answering four questionnaires, which will give us the information - about your fear of falling, depression, health status perception, and exercise activities. The estimated time for completion of this survey is approximately 15 to $20 \mathrm{~min}$. Your responses will be kept completely confidential and no individual responses will be released. If the study is published, it will be impossible for any participant to be identified.

By completing the questionnaires and returning them you give your consent to participate in this research. Participation in this research is voluntary and you are free to decline to participate. There is no direct benefit and no cost to you for participating in this research. There is no known risk for participation in this research. The anticipated benefit of this study is to determine the effects of a regular exercise group program in community dwelling elders with chronic stroke.

If you score 10 or above on the Geriatric Depression Scale (score of 10 or above indicates the presence of severe depression) and with your permission, you will be referred to Kathryn Bishopric, RN, MSN, LCSW, Manager at South Miami Hospital Counseling Services, who can be contacted at (786) 662-8106.

If you have any questions about this research, please contact Dessislava Dakova, PT at (786) 662 -5111 . If you have any further questions about participating in this research and/or your rights as a participant, you may contact Dr. Bernard Gerstman, Chairperson of the Institutional Review Board at Florida International University, at (305) 348-3115 or (305) 348-2494, Helen Cornely, MS PT, Associate Professor PT at Florida International University at (305) 348-1968 and Kelly Cohn, RN, Manager at Baptisf and South Miarai Mospital Institutional Review Board at (305) 596-1690 ext. 8680.

Thank you in advance for your participation.

Sincerely,<smiles>COC1=CC=CCC1</smiles>

Dessislava Dakova, PT

DEPARTMENT OF PhYSICAL THERAPY

College of Health

University Park - Miami, Florida 33199

relephone (305) 348-3831 - fax (305) 348-1240

www.fiu.edu

Equal Opportunicy/Equal Access Employer and Institution * TDD via FRS 200 955-8771 
APPENDIX B - DEMOGRAPHICS QUESTIONNAIRE 
1. Age:

2. Gender:

a Male 01

- Female 02

3. Highest level of education you have completed:

a Grade School

12345678

a High School

9101112

- College, Vocational School

13141516

- Some graduate or professional School

17

- Graduate or professional School

18

4.Where and with whom do you live now?

a At home:

a Alone 01

- With my husband/ wife 02

- With my children 03

○ In Retirement Home or ALF 04

5. Health conditions:

a Coronary Artery Disease 01

a Depression 02

a Hypertension 03

a Stroke 04

a Others 05

6. Haw many strokes have you had?

$\begin{array}{lll}\square & \text { One } & 01 \\ \square & \text { Two } & 02 \\ \square & \text { More } & 03\end{array}$

7. Time since the last stroke?

口 1-6 months 01

- 6 months -1 year 02

a More than 1 year 03 
8. Are you afraid of falling?

- Yes

- No

9. Physical Exercises.

- I have been exercising regularly more than 6 months 01

- I have been exercising regularly less than 6 months 02

- I am not exercising regularly

10. How many falls have you had in the past 6 months?

- One

口 Two

a More

03

a No falls

11. How do you rate your health today?

口 Poor

01

口 Fair

- Satisfactory

a Good

Excellent

13. How many times have you been hospitalized and for how long in the past year:

a Number of hospitalizations

a Days of hospitalization

02

14. Please check any devices that you usually use:
a Cane
01
a Walker
02
a Hemi Walker
03
口 Wheelchair
04

Thank you for participating in this study. 
APPENDIX C - FALLS EFFICACY SCALE 


\section{Falls Efficacy Scale}

1. For each question choose one number between 1 and 10 with 1 meaning not confident at all when performing the activity and 10 meaning extremely confident when performing the activity.

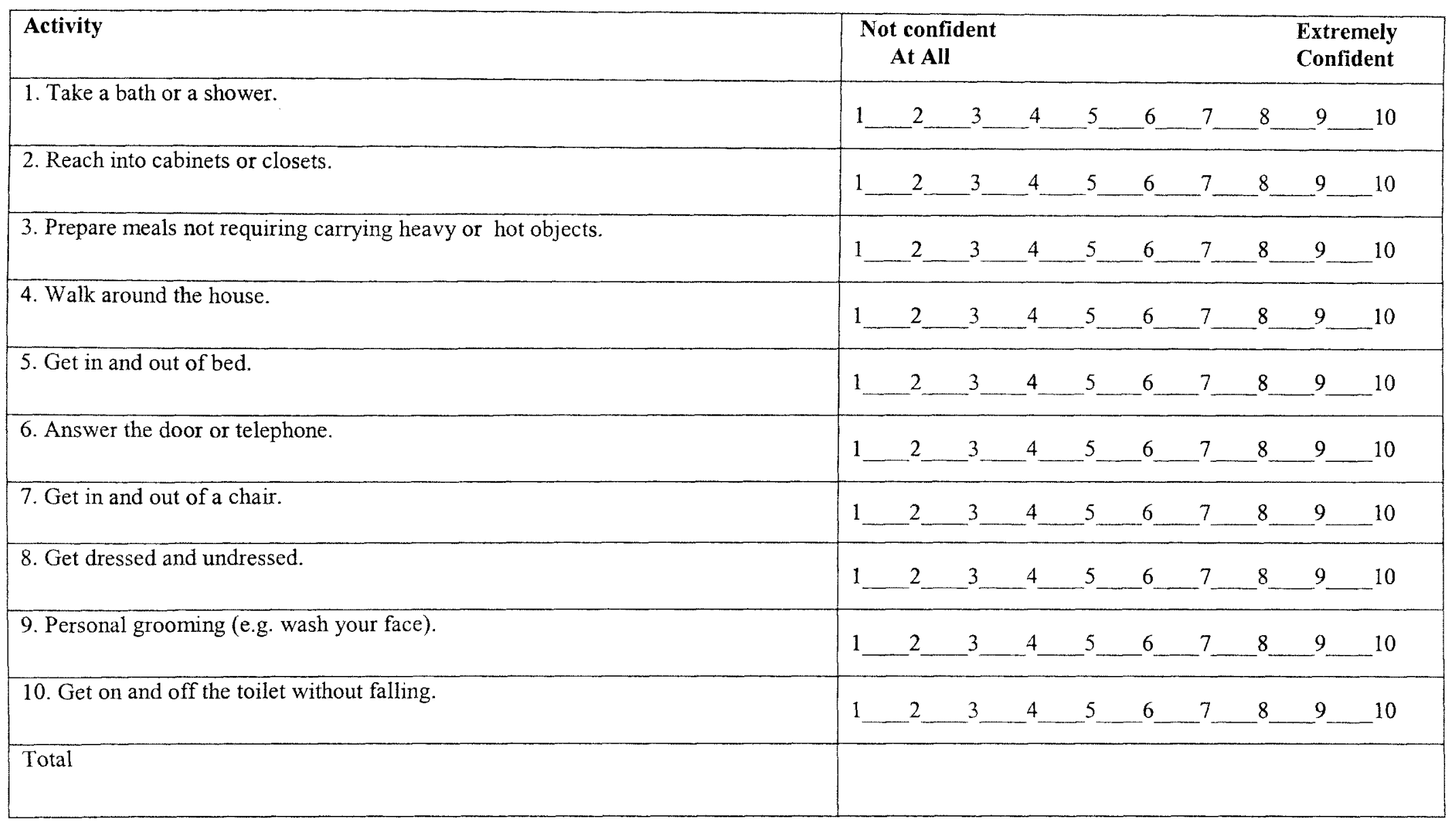

1. Tinetti ME, Rihman D, Powel L. Falls efficacyas a measure of fear of falling. J Gerontol Psych Sci. 1990;45:P239-43. 
APPENDIX D - GERIATRIC DEPRESSION SCALE SHORT FORM 


\section{$\underline{\text { Geriatric Depression Scale }}$}

- Cross off either yes or no for each question.

\begin{tabular}{|c|c|c|}
\hline 1. Are you basically satisfied with your life? & Yes & No \\
\hline 2. Have you dropped many of your activities and interests? & Yes & No \\
\hline 3. Do you feel happy most of the time? & Yes & No \\
\hline 4. Do you prefer to stay at home rather than going out and doing new things? & Yes & No \\
\hline 5. Do you feel that life is empty? & Yes & No \\
\hline 6. Do you often get bored? & Yes & No \\
\hline 7. Are you in good spirits most of the time? & Yes & No \\
\hline 8. Are you afraid that something bad is going to happen to you? & Yes & No \\
\hline 9. Do you feel helpless? & Yes & No \\
\hline 10. Do you feel that you have more problems with memory that most? & Yes & No \\
\hline 11. Do you think that is wonderful to be alive? & Yes & No \\
\hline 12. Do you feel pretty worthless the way you are now? & Yes & No \\
\hline 13. Do you feel full of energy? & Yes & No \\
\hline 14. Do you feel that your situation is hopeless? & Yes & No \\
\hline 15. Do you think that most people are better off than you are? & Yes & No \\
\hline Total & & \\
\hline
\end{tabular}

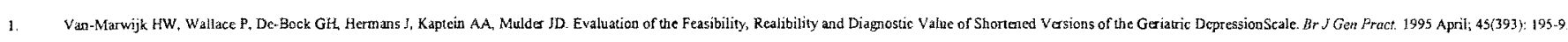

2. Neal RM. Baldwin RC. Screening for Anxiety and Depression in Eldely Medical Outpatiens. Age-Ageing 1994 November: 23(6): 461-4. 
APPENDIX E - HEALTH ASSESSMENT QUESTIONNAIREC 


\section{Health Assessment Questionnaire (HAQ)C}

1. For each question choose one number between 0 and 3 with 0 meaning not difficulty to perform the activity and 3 meaning unable to perform the activity.

\begin{tabular}{|c|c|c|c|c|}
\hline $\begin{array}{l}\text { The following are a list of activities with } \\
\text { which some people have difficulty. Please, } \\
\text { indicate whether you have "no difficulty", } \\
\text { "some difficulty", "much difficulty" or "are } \\
\text { unable to do" these activities at all when you } \\
\text { are by yourself and without the use of aids. }\end{array}$ & $\begin{array}{c}\text { No } \\
\text { difficulty }\end{array}$ & $\begin{array}{c}\text { Some } \\
\text { difficult } \\
y\end{array}$ & $\begin{array}{l}\text { Much } \\
\text { difficulty }\end{array}$ & $\begin{array}{c}\text { Unable } \\
\text { to do }\end{array}$ \\
\hline $\begin{array}{l}\text { 1. Dress yourself including tying shoes, } \\
\text { working zippers and doing buttons. }\end{array}$ & 0 & 1 & 2 & 3 \\
\hline 2. Shampoo your hair. & 0 & 1 & 2 & 3 \\
\hline \multicolumn{5}{|l|}{ Total category \#1 } \\
\hline 3. Stand up from an armless chair. & 0 & 1 & 2 & 3 \\
\hline 4. Get into and out of bed. & 0 & 1 & 2 & 3 \\
\hline \multicolumn{5}{|l|}{ Total category \#2 } \\
\hline 5. Cut your meat. & 0 & 1 & 2 & 3 \\
\hline 6. Lift a full cup or glass to your mouth. & 0 & 1 & 2 & 3 \\
\hline 7. Open a new milk carton. & 0 & 1 & 2 & 3 \\
\hline \multicolumn{5}{|l|}{ Total category $\# 3$} \\
\hline 8. Walk outdoors on flat ground. & 0 & 1 & 2 & 3 \\
\hline 9. Walk up and down five steps. & 0 & 1 & 2 & 3 \\
\hline \multicolumn{5}{|l|}{ Total category \#4 } \\
\hline 10. Get in and out of the bathtub. & 0 & 1 & 2 & 3 \\
\hline 11. Wash and dry your whole body. & 0 & 1 & 2 & 3 \\
\hline 12. Get on and off the toilet. & 0 & 1 & 2 & 3 \\
\hline \multicolumn{5}{|l|}{ Total category \#5 } \\
\hline $\begin{array}{l}\text { 13. Reach and get down a } 5 \text { pound object (bag } \\
\text { of sugar) from just above your head. }\end{array}$ & 0 & 1 & 2 & 3 \\
\hline $\begin{array}{l}\text { 14. Bend down and pick up clothing from the } \\
\text { floor. }\end{array}$ & 0 & 1 & 2 & 3 \\
\hline \multicolumn{5}{|l|}{ Total category $\# 6$} \\
\hline 15. Open car doors. & 0 & 1 & 2 & 3 \\
\hline $\begin{array}{l}\text { 16. Open jars that have been previously } \\
\text { opened. }\end{array}$ & 0 & 1 & 2 & 3 \\
\hline 17. Turn faucets on and off. & 0 & 1 & 2 & 3 \\
\hline \multicolumn{5}{|l|}{ Total category \#7 } \\
\hline 18. Get in and out of a car. & 0 & 1 & 2 & 3 \\
\hline 19. Run errands and shop. & 0 & 1 & 2 & 3 \\
\hline 20. Do light chores such as vacuuming. & 0 & 1 & 2 & 3 \\
\hline Total category \#8 & & & & \\
\hline
\end{tabular}

1.Ramrey DR, Fries G. in B.Spilker Quclity of life and Pharmacoleconomics in Clinical Trials, 2nd ed., The Health assessment Questionnaire 1995 - Status and review. Philadelphia: Lippincott-Raven Pub., 1996, p 227-237.

2.Fries JF, Spitz P, Kraines G, Holman H. Measurenent of Patient outcome in arthritis.Arthrilis and Rheumatism. 1980;23:137-145. 